\title{
ESTUDO PETROLÓGICO DE ALGUNS FRAGMENTOS TECTÔNICOS DA MELANGE OFIOLÍTICA EM ABADIÂNIA (GO): I - O PROTOLITO DOS CORPOS DE SERPENTINITO
}

\author{
ADELIR J. STRIEDER* \& ARIPLÍNIO A. NELSON**
}

\begin{abstract}
PETROLOGICAL STUDY OF SOME TECTONIC FRAGMENTS OF THE OPffIOLITIC MÉLANGETN ABADIÂNIA (GO): I-THE PROTOLITH OF THE SERPENTINITE BODIES. A group of nine serpentinite bodies was recognized in the Abadiania region (GO); they are technically emplaced in the Araxá metasediments and has been interpreted as exotic fragments of a ophiolitic melange. This paper presents a petrochemical study of the bilateral metasomatic mass transfer between the serpentinites and their country rocks, aiming to determine the degree of chemical modification of the initial ultramafic protolith. Then, the serpentinite bodies were systematically described and characterized with regard to their internal constitution, deformation and metamorphism. This approach showed that chemical modification was restricted to the metasomatic zones and their vicinities, and allowed the selection of adequate samples for the geochemical affinity study of serpentinites and chromitites. In this way, it was finally concluded that serpentinites show a residual harzburgite geochemical composition, in accordance with the highly aluminous nature of the associated podiform chromitite. These structural and petrochemical characteristics show that these bodies are tectonically dismembered fragments of an ophiolitic pile.
\end{abstract}

Keywords: Ophiolitic fragments, serpentinite, petrochemical treatment, metasomatism.

\begin{abstract}
RESUMO Um grupo de nove corpos de serpentinito foi reconhecido na região de Abadiânia (GO); eles estão tectonicamente alojados nos metassedimentos Araxá e têm sido interpretados como fragmentos exóticos de uma melange ofiolítica. Este artigo apresenta um estudo petroquímico da transferência metassomática bilateral de massa entre os serpentinitos e as suas rochas encaixantes, com o objetivo de determinar o grau de modificação química do protolito ultramáfico inicial. Deste modo, os corpos de serpentinito foram sistematicamente descritos e caracterizados com relação a sua constituição interna, deformação e metamorfismo. Este exame mostrou que a modificação química foi restringida às zonas metassomáticas e às suas vizinhanças, e permitiu a seleção das amostras mais adequadas para o estudo da afinidade geoquímica dos serpentinitos e dos cromititos. Assim, foi finalmente concluído que os serpentinitos têm a composição geoquímica de harzburgitos residuais, o que está em acordo com a natureza altamente aluminosa dos cromititos podiformes associados. Estas características petroquímicas e estruturais mostram que tais corpos são fragmentos tectonicamente desmembrados de uma "pilha" ofiolítica.
\end{abstract}

Palavras-chaves: Fragmento ofiolítico, serpentinito, tratamento petroquímico, metassomatismo.

INTRODUÇÃO Vários corpos máficos e ultramáficos alojados nos metassedimentos Araxá têm sido referidos em mapeamentos regionais efetuados na região Centro-Oeste (Corrêa \& Bittencourt 1968, Batista 1969, Braun 1969, Nilson \& Motta 1969, Berbert et al. 1970). As condições do seu alojamento são encaradas de formas diversas, embora ainda pareça ser mais adotada a interpretação de que os corpos de serpentinito foram alojados através de intrusões "a frio" em grandes falhas regionais como decorrência da concordância entre as foliações de bordo dos corpos e aquela das rochas encaixantes (Berbert 1970, Drake 1980, Danni \& Teixeira 1981). A natureza destas intrusões, contudo, nem sempre foi bem compreendida, na medida em que não são registradas quaisquer estruturas claramente intrusivas nestes corpos. Mais recentemente, Nilson $(1981,1984)$ tem sugerido que estas rochas representam fatias tectonicamente alojadas nas rochas metassedimentares.

Estes aspectos vinham demonstrando a necessidade de um estudo comparativo detalhado das feições estruturais que ocorrem nos corpos de serpentinito, nas rochas máficas e nas rochas metassedimentares encaixantes; mostravam, também, a necessidade de um avanço na discussão da natureza petrotectônica da associação formada por estas rochas e as rochas metassedimentares encaixantes.

Em termos gerais, as lacunas existentes para a avaliação da natureza dos corpos máficos e ultramáficos e do tipo de as- sociação petrotectônica que formam com os metassedimentos Araxá começaram a ser preenchidos a partir de Strieder (1989), que fornece uma discussão simplificada, mas conjunta, de todos os aspectos mais importantes desta avaliação. Posteriormente, a partir da análise estrutural detalhada da região de Abadiânia (GO), Strieder (1990) mostra 1. que todas as superfícies deformacionais presentes nas rochas metassedimentares encaixantes são identificadas nos corpos máficos e ultramáficos, 2. que há uma concordância bem marcada entre a deformação impressa nos corpos ultramáficos e máficos e aquela impressa nas rochas metassedimentares encaixantes e 3. que o alojamento destes corpos se deu durante uma fase de intensa milonitização regional $\left(D_{1}\right)$. Estas feições também podem ser identificadas em outros corpos máficos e ultramáficos que ocorrem encaixados nos metassedimentos Araxá (Berbert 1970, Nilson 1984).

Os resultados gerais da análise estrutural realizada por Strieder (1990), a semelhança das feições registradas em outros corpos máficos e ultramáficos encaixados nos metassedimentos Araxá e a estreita relação entre a ocorrência desta associação litológlca e de fortes anomalias gravimétricas Bouger permitiram que Strieder \& Nilson (1992) caracterizassem esta associação como um depósito de calha de subducção (melange ofiolítica).

Assim, os trabalhos reunidos sob o título geral "Estudo petrológico de alguns fragmentos tectônicos da melange ofiolí-

\footnotetext{
* Centro de Estudos em Petrologia e Geoquímica, Instituto de Geociências, Universidade Federal do Rio Grande do Sul, Avenida Bento Gonçalves, 9500, Caixa Postal 15001, CEP 91501-970, E-mail: Adelir@IFl.UFRGS.BR, Porto Alegre, RS, Brasil

** Departamento de Mineralogia e Petrologia, Instituto de Geociências, Universidade Federal de Brasília, Asa Norte, CEP 70719-970, Brasília, DF, Brasil
} 
tica em Abadiânia (GO)" vêm preencher uma parte das lacunas existentes para a caracterização da melange ofiolítica. Entretanto, este trabalho não pretende fazer uma generalização dos resultados petrográficos e petroquímicos obtidos nas rochas da região de Abadiânia, porque certamente devem existir vários tipos litológicos que foram desmembrados e alojados nesta associação petrotectônica e porque a sua exata caracterização se dá com a definição correta das superfícies regionais de cavalgamento (Strieder \& Nilson 1992). Portanto, estes trabalhos pretendem fornecer as bases do tratamento petrológico para a identificação e a definição de uma parte dos litotipos que estão envolvidos na melange ofiolítica.

Com relação aos corpos de serpentinito, percebe-se que nenhum estudo sistemático e detalhado das suas características petrográficas e petroquímicas foi ainda realizado. De um modo geral, os corpos de serpentinito são indicados como "corpos do tipo alpino" a partir, principalmente, das características petrográficas de bolsões de cromitito podiforme que lhes estão associados. Desta forma, este primeiro trabalho pretende abor- dar as características estruturais e petrográficas, as transformações metamórficas sofridas e as afinidades geoquímicas do protolito inicial dos nove pequenos corpos ultramáficos individualizados na região de Abadiânia (GO).

MÉTODOS ANALÍTICOS As análises químicas de elementos maiores e menores (Tab. 1) foram realizadas no Laboratório de Geoquímica da Universidade de Brasília através do método via-úmida, que emprega metodologia interna especificada por Boaventura \& Hirson (1987). Os elementos traços $(\mathrm{V}, \mathrm{Y})$ e Terras Raras foram respectivamente analisados através de Fluorescência de Raios-X e Espectrometria de Plasma (ICP) na Divisão de Laboratórios da GEOSOL (Tab. 2). Em ambos os laboratórios, a utilização de amostras em duplicata mostrou boa reprodutibilidade das análises.

A análise dos minerais dos campos da serpentina e das cloritas por difratometria de raios-X utilizou radiação $\mathrm{CuK} \alpha$, velocidade de varredura de $8^{\circ} 20 / \mathrm{min}$, constante de tempo de 4 seg e velocidade do papel de $4 \mathrm{~mm} / \mathrm{grau}$.

Tabela 1 - Análises químicas de elementos maiores (\% peso) e menores (ppm) dos tipos litológicos que compõem os corpos de serpentinito e a rocha encaixante

Table 1- Major (weight \%) and minor (ppm) elements chemical analysis of the serpentinite bodies and country rock lithitypes

\begin{tabular}{|c|c|c|c|c|c|c|c|c|c|c|c|c|c|c|c|c|c|c|c|c|c|c|}
\hline & $\mathrm{SiO}_{1}$ & $\mathrm{AJ}_{2} \mathrm{O}_{3}$ & $\mathrm{~F} e_{2} \mathrm{O}$ & $\mathrm{F}=\mathrm{O}$ & $\mathrm{C}=0$ & $\mathrm{MgO}$ & $\mathrm{Na}_{2} \mathrm{O}$ & $k_{q}, 0$ & MnO & $\mathrm{P}_{2} \mathrm{O}_{3}$ & $\mathrm{TO}_{\mathbf{1}}$ & P.F. & $\mathbf{c u}$ & Pt & $\mathbf{Z n}$ & $\mathrm{Ni}$ & $\mathbf{C r}$ & $C$ & $\mathbf{L}$ & $\mathbf{R b}$ & c & FeO* \\
\hline \multicolumn{23}{|c|}{ Sepentinitos } \\
\hline $\operatorname{CS} 102 \mathrm{M}$ & 45,05 & 1,92 & 4,76 & 236 & 033 & 29,80 & 0,10 & 0,10 & 0,07 & 0,09 & 0,02 & 12,99 & 10 & 6 & 21 & 2110 & 1320 & 90 & 3 & 9 & 54 & 6,64 \\
\hline $\csc 0 \mathrm{~N}$ & 41,23 & 1,56 & 4,68 & 2,46 & 0,56 & 34,75 & 0,10 & 0,10 & 0,08 & 0,12 & 0,04 & 13,54 & 16 & 5 & 37 & 1870 & 1700 & 87 & 1 & 9 & 59 & 16,67 \\
\hline $\csc 05 \mathrm{~B}$ & 35,92 & 1,29 & 0,77 & 6,13 & 1,02 & 31,29 & 0,10 & 0,10 & 0,08 & 0,03 & 0,07 & 23,13 & 15 & 5 & 40 & 1990 & 1730 & 95 & 1 & 9 & 59 & 6,82 \\
\hline $\operatorname{cs} 205 \mathrm{E}$ & 35,42 & 1,87 & 0,71 & 4,67 & 0,50 & 35,58 & 0,10 & 0,10 & 0,08 & 0,09 & 0,02 & 19,89 & 8 & 9 & 39 & 1250 & $16 \$ 0$ & 32 & I & 9 & 50 & 5,31 \\
\hline $\operatorname{Cs} 472 \mathrm{~A}$ & 42,30 & 1,46 & 5,08 & 2,41 & 0,23 & 35,38 & 0,10 & 0,10 & 0,10 & 0,16 & 0,03 & 11,87 & 2 & 4 & 43 & 2130 & $\mathbf{2 3 0 0}$ & 92 & $\mathbf{J}$ & 9 & 58 & 6,98 \\
\hline $\operatorname{Cs} 472 \mathrm{E}$ & 42,80 & 1,69 & 3,78 & 3,34 & 0,30 & $34, \pi$ & 0,10 & 0,10 & 0,09 & 0,17 & 0,04 & 11,84 & 30 & 6 & 38 & 2160 & 2300 & 90 & 1 & 9 & 58 & 6,74 \\
\hline CS6880 & 41,91 & 1,19 & 2,64 & 2,43 & 1,16 & 35,75 & 0,10 & 0,10 & 0,08 & 0,02 & 0,04 & 13,31 & 10 & 8 & 35 & 1970 & 1790 & 81 & 1 & 9 & 58 & 4,81 \\
\hline CS7 BoF & 40,90 & 1.72 & 5.19 & 5,07 & 0,76 & 33,19 & 0,10 & 0.10 & 0,10 & 0,01 & 0.46 & 12,97 & 105 & 3 & 41 & $2 m 0$ & 1900 & 105 & 1 & 14 & 74 & 9,74 \\
\hline Csi tha & 40,23 & 2,75 & 5,98 & 2,45 & 0,53 & 33,59 & 0,01 & 0,06 & 0,14 & 0,20 & 0,0 & 14,52 & 15 & 7 & 35 & 20020 & 1350 & 87 & 1 & 9 & 54 & 7,83 \\
\hline $\operatorname{cs} 102 k$ & 38,81 & 1.62 & 4,33 & 1,81 & 0,70 & 40,77 & 0,01 & 0,07 & 0,06 & 0,04 & 0.02 & 12,23 & 14 & 10 & $2 \pi$ & 1950 & 1400 & 88 & 2 & 9 & 65 & $\$, 71$ \\
\hline $\operatorname{Cs} 205 \mathrm{~A}$ & 37,82 & 1,61 & 1,64 & 4,74 & 1,79 & 35,66 & 0,10 & 0,10 & 0,10 & 0,08 & 0,14 & 16,69 & 14 & 9 & 31 & 1140 & 1740 & 39 & 1 & 4 & 39 & 6,22 \\
\hline $\operatorname{cs} 205 F$ & 47,06 & 2,20 & 020 & 4,65 & 0,13 & 33,01 & 0,01 & 0,11 & 0,04 & 0,01 & 0,04 & 12,86 & 25 & 12 & 34 & 1990 & 950 & 74 & 2 & 4 & 50 & 4,83 \\
\hline CS7 89E & 39,91 & 1,04 & 3,38 & 4,05 & 0,10 & 35,86 & 0,01 & 0,10 & 0,09 & 0,01 & 0,04 & 13,87 & 4 & 8 & 31 & 2760 & 1470 & 90 & $\mathbf{I}$ & 9 & 99 & 7,09 \\
\hline $\operatorname{cscosc}$ & 36,75 & 3,03 & 1,15 & 5,70 & 1,56 & 35,24 & 0,02 & 0,01 & 0,09 & 0,05 & 0.01 & 14,45 & 16 & II & 49 & 1820 & 2560 & 90 & 1 & 15 & 52 & 6,73 \\
\hline $\cos 33 \mathrm{~B}$ & 34,46 & 0,74 & 252 & 3,61 & 0,31 & 33,81 & 0,02 & 0,01 & 0,08 & 0,20 & 0,05 & 34,02 & 8 & 5 & 27 & 1620 & 2060 & 80 & 3 & 4 & 39 & 5,88 \\
\hline
\end{tabular}

\section{Taleo xistas}

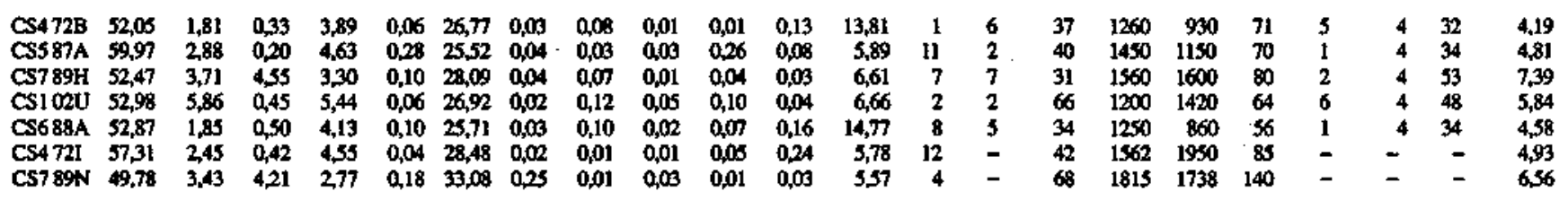

Clorib-remolian xisto

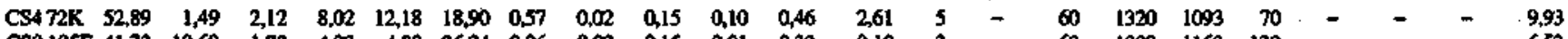
$\begin{array}{ccccccccccccccccccccccc}\cos 105 \mathrm{E} & 41,73 & 10,60 & 1,78 & 4,93 & 4,82 & 26,24 & 0,06 & 0,02 & 0,15 & 0,01 & 0,32 & 9,10 & 3 & - & 62 & 1298 & 1160 & 120 & - & - & - & 6,53\end{array}$

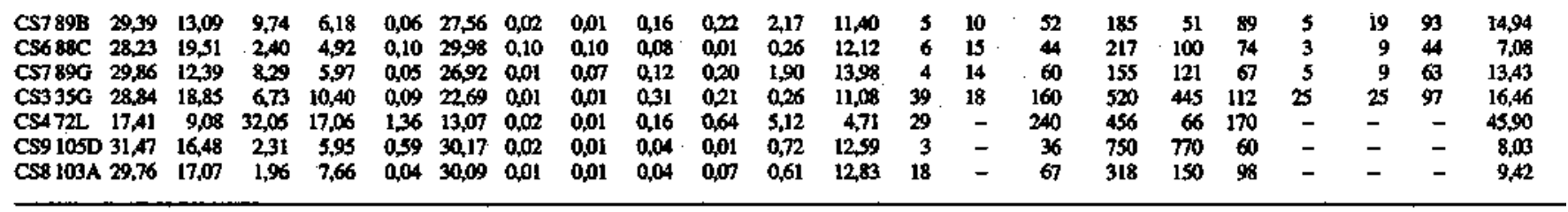

Granti-migrquartooxiswo

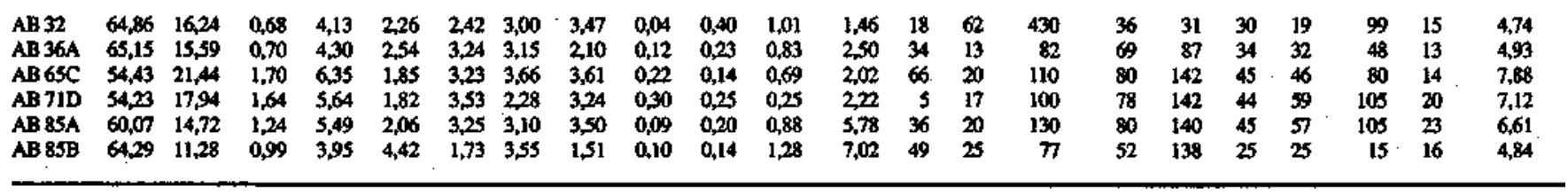


Tabela 2-Análises químicas de elementos traços e ETR (ppm) de alguns tipos litológicos dos corpos ultramáficos; (l.d.) resultados abaixo do limite de detecção

Table 2 - Trace and RE elements (ppm) chemical analysis of some ultramafic bodies lithotypes. (Id.) values lower than detection limit

\begin{tabular}{|c|c|c|c|c|c|c|c|c|c|c|c|c|c|}
\hline & $\mathbf{v}$ & $\mathbf{X}$ & Ce & $\mathbf{S m}$ & La & $\mathbf{Y b}$ & Nd & $\mathrm{Eu}$ & Gd & Dy & Ex & $\mathbf{L M}$ & Ho \\
\hline \multicolumn{14}{|c|}{ Serpentinitos } \\
\hline $\begin{array}{l}\operatorname{CS1} 102 \mathrm{~K} \\
\operatorname{CS2} 205 \mathrm{E} \\
\operatorname{CS} 472 \mathrm{~A} \\
\operatorname{CS1} 02 \mathrm{~N} \\
\operatorname{CS} 688 \mathrm{D}\end{array}$ & $\begin{array}{l}70,00 \\
55,00 \\
62,00 \\
62,00 \\
73,00\end{array}$ & $\begin{array}{l}11,00 \\
11, \infty 0 \\
10,00 \\
10,00 \\
10.00\end{array}$ & $\begin{array}{l}1,10 \\
0,91 \\
1,40 \\
\text { 1.d. } \\
\text { 1.d. }\end{array}$ & $\begin{array}{l}0,11 \\
0,29 \\
0,15 \\
\text { l.d. } \\
\text { l.d. }\end{array}$ & $\begin{array}{l}1,04 \\
0,85 \\
0,90 \\
\text { l.d. } \\
\text { Ld. }\end{array}$ & $\begin{array}{r}0,11 \\
0,24 \\
0,21 \\
\text { 1.d. } \\
\text { 1.d. }\end{array}$ & $\begin{array}{l}0,44 \\
0,83 \\
0,53 \\
\text { l.d. } \\
\text { l.d. }\end{array}$ & $\begin{array}{l}0,06 \\
0,11 \\
0,08 \\
\text { l.d. } \\
\text { l.d. }\end{array}$ & $\begin{array}{l}0,17 \\
0,38 \\
0,25 \\
\text { l.d. } \\
\text { l.d. }\end{array}$ & $\begin{array}{l}0,12 \\
0,29 \\
0,20 \\
\text { I.d. } \\
\text { l.d. }\end{array}$ & $\begin{array}{l}0,08 \\
0,20 \\
0,17 \\
\text { l.d. } \\
\text { 1.d. }\end{array}$ & $\begin{array}{l}0,04 \\
0,07 \\
0,06 \\
\text { l.d. } \\
\text { l.d. }\end{array}$ & $\begin{array}{l}0,04 \\
0,06 \\
0,06 \\
\text { I.d. } \\
\text { i.d. }\end{array}$ \\
\hline \multicolumn{14}{|c|}{ Talco xisto } \\
\hline $\operatorname{CSt} 02 B$ & 720,00 & 10,00 & 12,40 & 1.20 & 6,10 & 0,40 & 9,40 & 1,10 & 1,50 & 1,10 & 0,52 & 0,05 & 0,20 \\
\hline \multicolumn{14}{|c|}{ Clorita xisto } \\
\hline CS7890 & 178,00 & 46,00 & 133,90 & 14,70 & 66,40 & 2,00 & 70,60 & 4,40 & 10,30 & 5,60 & 2,60 & 0,29 & 0,93 \\
\hline
\end{tabular}

Tabela 3 - Composição normativa (CPIW) dos serpentinitos da região de Abadiânia, calculada em base anidra, sem $\mathrm{CO}_{2}$ e com $\mathrm{FeO} *$

Table 3 -CPIW normative composition of the serpentinites, calculated in anhydrous base, without $\mathrm{CO}_{2}$ and total iron as FeO*

\begin{tabular}{|c|c|c|c|c|c|c|c|c|c|c|c|c|c|c|c|c|c|}
\hline & $\mathbf{Q}$ & $\mathbf{\alpha}$ & $\mathbf{A B}$ & $\mathbf{A N}$ & wo & DI & EN & $\mathbf{F s}$ & $\mathbf{H Y}$ & $\mathbf{F O}$ & $\mathbf{F A}$ & a. & $\mathbf{L}$ & $\boldsymbol{A} \mathbf{P}$ & $\mathbf{O M}$ & \$EN & \$FO \\
\hline 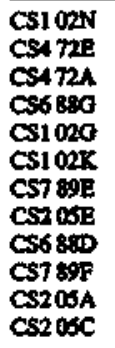 & $\begin{array}{l}0,65 \\
1,47 \\
1,32 \\
0,00 \\
2,55 \\
0,40 \\
0,90 \\
1,14 \\
0,87 \\
0,10 \\
0,00 \\
0,32\end{array}$ & $\begin{array}{l}0,69 \\
0,69 \\
0,68 \\
0,69 \\
0,41 \\
0,47 \\
0,70 \\
0,75 \\
0,68 \\
0,68 \\
0,70 \\
0,07\end{array}$ & $\begin{array}{l}099 \\
097 \\
097 \\
099 \\
0,10 \\
010 \\
0,10 \\
1,07 \\
097 \\
097 \\
1,01 \\
020\end{array}$ & $\begin{array}{l}2,33 \\
0,43 \\
0,11 \\
2,93 \\
1,55 \\
3,65 \\
0,51 \\
2,39 \\
0,19 \\
4,24 \\
4,35 \\
2,44\end{array}$ & $\begin{array}{l}0,00 \\
0,00 \\
0,00 \\
0,00 \\
0,00 \\
0,00 \\
0,00 \\
0,00 \\
0,00 \\
0,00 \\
0,00 \\
0,00\end{array}$ & $\begin{array}{l}0,00 \\
0,00 \\
0,00 \\
2,87 \\
0,00 \\
0,00 \\
0,00 \\
0,00 \\
0,00 \\
0,00 \\
4,43 \\
0,00\end{array}$ & $\begin{array}{l}37,94 \\
45,17 \\
42,17 \\
37,22 \\
38,13 \\
15,28 \\
34,22 \\
19,11 \\
38,09 \\
32,08 \\
16,92 \\
15,69\end{array}$ & $\begin{array}{l}5,31 \\
6,36 \\
6,05 \\
3,63 \\
6,57 \\
1,56 \\
4,95 \\
2,06 \\
5,76 \\
6,62 \\
2,11 \\
2,16\end{array}$ & $\begin{array}{l}43,25 \\
51,53 \\
44,23 \\
40,85 \\
44,70 \\
16,84 \\
39,17 \\
21,19 \\
43,85 \\
38,70 \\
10,94 \\
17,67\end{array}$ & $\begin{array}{l}44,39 \\
37,94 \\
41,14 \\
44,11 \\
41,80 \\
70,15 \\
50,12 \\
64,92 \\
45,60 \\
43,44 \\
61,13 \\
62,35\end{array}$ & $\begin{array}{l}6,85 \\
5,99 \\
6,52 \\
4,96 \\
7,94 \\
790 \\
8,00 \\
7,80 \\
7,51 \\
9,96 \\
8,46 \\
9,54\end{array}$ & $\begin{array}{l}51,24 \\
49,02 \\
47,65 \\
51,07 \\
49,74 \\
78,06 \\
58,12 \\
72,71 \\
52,57 \\
53,02 \\
60,60 \\
71,69\end{array}$ & $\begin{array}{l}0,09 \\
0,09 \\
0,07 \\
0,09 \\
0,07 \\
0,04 \\
0,09 \\
0,05 \\
0,07 \\
1,00 \\
0,32 \\
0,02\end{array}$ & $\begin{array}{l}0,33 \\
0,46 \\
0,43 \\
0,06 \\
0,55 \\
0,11 \\
0,03 \\
0,27 \\
0,41 \\
0,03 \\
0,23 \\
0,14\end{array}$ & $\begin{array}{l}0,49 \\
0,56 \\
0,56 \\
0,45 \\
0,34 \\
0,35 \\
0,38 \\
0,45 \\
0,41 \\
0,47 \\
0,44 \\
0,65\end{array}$ & $\begin{array}{l}87,70 \\
87,70 \\
87,00 \\
91,10 \\
85,30 \\
90,70 \\
87,40 \\
90,20 \\
86,90 \\
82,90 \\
88,80 \\
87,80\end{array}$ & $\begin{array}{l}86,60 \\
86,60 \\
86,30 \\
90,30 \\
84,10 \\
89,90 \\
86,30 \\
89,30 \\
85,70 \\
81,30 \\
87,50 \\
86,80\end{array}$ \\
\hline \multicolumn{18}{|c|}{ 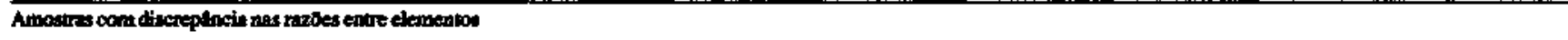 } \\
\hline $\begin{array}{l}\operatorname{cs1} 0 \mathrm{MM} \\
\operatorname{cs} 205 \mathrm{~B} \\
\operatorname{Cs} 20 \mathrm{~F} \\
\text { AL 14R }\end{array}$ & $\begin{array}{l}0,15 \\
0,00 \\
2,11 \\
3,29\end{array}$ & $\begin{array}{l}0,70 \\
077 \\
0,74 \\
0,41\end{array}$ & $\begin{array}{l}1,00 \\
1,10 \\
0,10 \\
4,29\end{array}$ & $\begin{array}{l}1,24 \\
3,61 \\
0,66 \\
0,00\end{array}$ & $\begin{array}{l}0,00 \\
0,00 \\
0,00 \\
0,00\end{array}$ & $\begin{array}{l}0,00 \\
2,15 \\
0,00 \\
0,00\end{array}$ & $\begin{array}{l}65,76 \\
26,90 \\
69,62 \\
38,40\end{array}$ & $\begin{array}{r}10,73 \\
4,26 \\
7,41 \\
3,33\end{array}$ & $\begin{array}{l}76,49 \\
31,15 \\
77,03 \\
43,73\end{array}$ & $\begin{array}{l}15,61 \\
51,50 \\
17,01 \\
41,46\end{array}$ & $\begin{array}{l}2,81 \\
0,90 \\
2,00 \\
6,4\end{array}$ & $\begin{array}{l}18,42 \\
60,49 \\
19,00 \\
47,80\end{array}$ & $\begin{array}{l}0,05 \\
0,17 \\
0,09 \\
0,00\end{array}$ & $\begin{array}{l}0,25 \\
0,09 \\
0,03 \\
0,11\end{array}$ & $\begin{array}{l}0,35 \\
0,48 \\
0,24 \\
0,99\end{array}$ & $\begin{array}{l}86,00 \\
86,40 \\
90,40 \\
17,80\end{array}$ & $\begin{array}{l}84,70 \\
85,10 \\
89,0 \\
86,80\end{array}$ \\
\hline
\end{tabular}

CARACTERIZAC̃̃ O PETROGRÁ FICA DOS CORPOSDE SERPENTINITO O termo genérico "Corpos de Serpentinito"engloba as rochas formadas por uma paragênese antigorita+magnetita (serpentinitos propriamente dito) e as rochas metassomáticas (xistos magnesianos) que lhes estão associados. Na região de Abadiânia, ocorrem nove pequenos corpos de serpentínito, que possuem área aflorante entre $0,4 \mathrm{e} 0,04 \mathrm{~km}^{2} \mathrm{e}$ que foram denominados por Corpo de Serpentínito l (CS1), CS2 .... CS9.

Os corpos de serpentínito aparecem em posições estruturais bem definidas ao longo de um ou mais dos segmentos de deformação em que foi compartimentada a regiâo (Fig. 1). Entretanto, não foi encontrada qualquer evidência de que possam representar fragmentos "estrangulados" a partir de um único corpo durante as fases de deformação impressas na região, embora a disposição de alguns deles possa sugerir isso; como foi mostrado por Strieder (1990), a disposição atual, simplesmente, o resultado do desenvolvimento alcançado pela última fase deformacional $\left(\mathrm{D}_{3}\right)$.

O pequeno tamanho dos corpos de serpentinito com relação macro-deformação da região faz com que eles não apresentem dobramentos internos e, portanto, normalmente não possuam repetições do arranjo concêntrico das zonas metassomáticas; a única exceção o CS7, onde meso-dobras $\mathrm{F}_{2}$ (Foto 1) explicam a ocorrência de zonas metassomáticas no interior de sua área aflorante. Outra característica importante é a quantidade extremamente pequena de veios de crísotila; os raros veios que ocorrem possuem espessura média menor do que $10 \mathrm{~mm}$.

O tamanho dos corpos de serpentinito, contudo, não impede que sejam observados, em maior ou em menor intensidade, todas as superficies deformacionais impressas nas rochas metassedimentares encaixantes. As características petrográficas de cada superfície deformacional serão descritas independentemente para os serpentinitos e para os xistos magnesianos.

Serpentinitos A xistosidade $S_{1}$ está invariavelmente transposta pelas superfícies desenvolvidas nas fases deformacionais seguintes. A foto 2 mostra que esta xistosidade marcada por grandes lamelas de serpentina, que sugerem uma textura geral do tipo ribbon (Maltman 1978). Nas amostras onde a textura ribbon reconhecida, pode-se também identificar alguns pseudomorfos sobre piroxênio (enstatita alterada) e olivina. Os primeiros (Foto 3) têm tamanho subcentimétrico e são aparentemente euédricos, pois são trancados lateralmente pelas lamelas de serpentina ribbon; apresentam, ainda, uma alternância de lamelas límpidas e de lamelas com diminutos grãos opacos, o que lhes dá um aspecto semelhante àquele descrito por Wicks \& Whittaker (1977) para enstatita alterada 


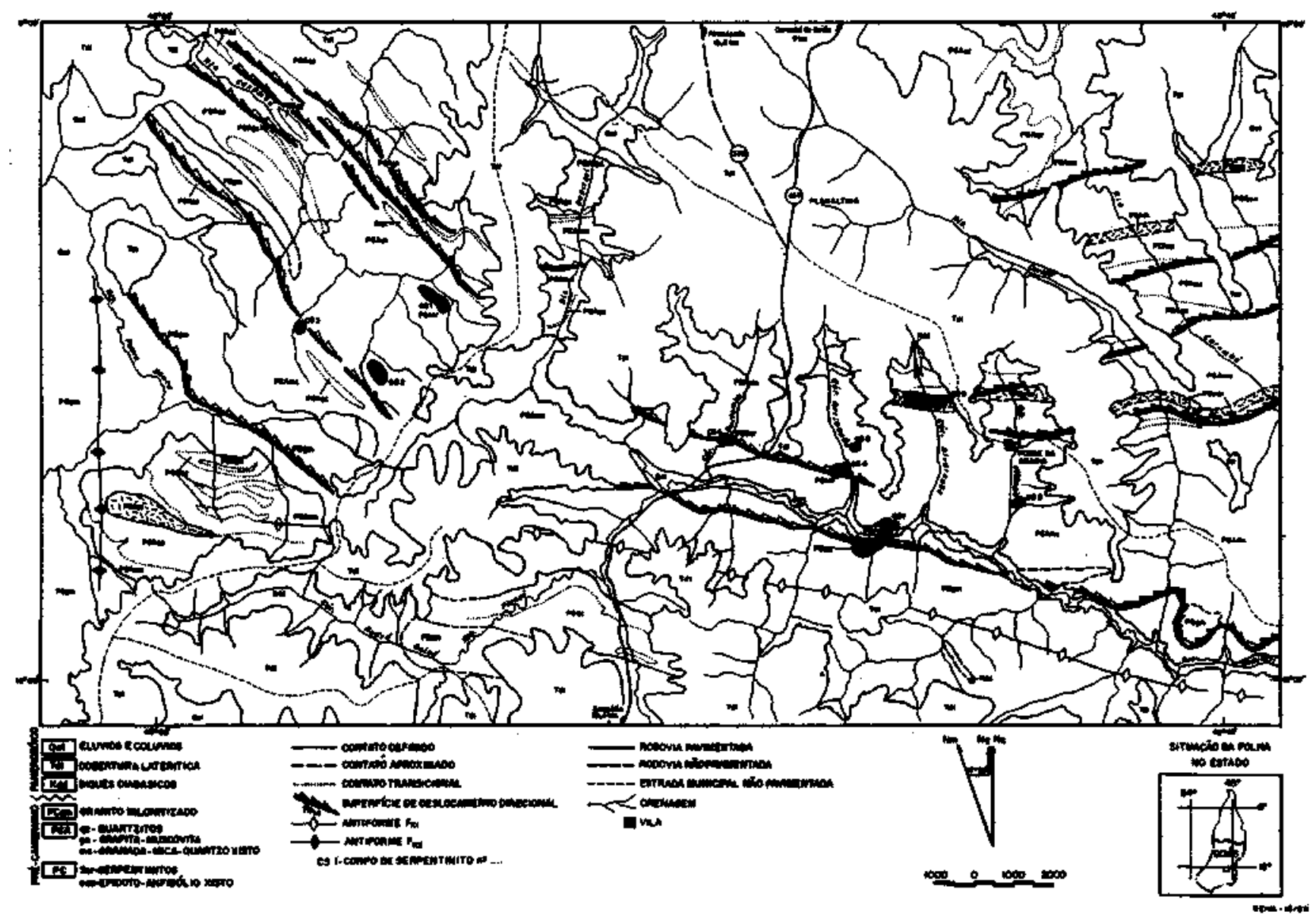

Figura 1 - Mapa geológico da região de Abadiaria (GO)

Figure 1 - Geologic map of the Abadiãnia region (GO)

com exsoluções de clinopiroxênio. Os pseudomorfos de olivina (Foto 4) são nódulos monominerálicos de serpentina límpida circundados por magnetita xenoblástica.

A xistosidade $\mathrm{S}_{2}$ está localmente desenvolvida na forma de um bandamento sub-centimétrico, no qual são preservadas algumas estruturas mesolitons de crenulação do tipo dobra (Foto 1), ou cisalhamento (Foto 5). A completa transposição por $\mathrm{S}_{2}$ dá origem a uma xistosidade fina e bem desenvolvida. As hneações $\mathrm{B}^{2}{ }_{1}$ destas rochas representam, então, eixos de crenulação medidos nas estruturas mesolitons. Microscopicamente, a xistosidade $S_{2}$ tem uma textura lepidoblástica fina, que possui estruturas microlitons de tamanho centimétrico.Os microlitons isolam microdobras e lentículas de serpentina ribbon, ou lentículas de magnetita grossa e serpentina ribbon com ou sem carbonato e/ou talco. Em algumas ocasiões, podese ainda observar finas vênulas com serpentina e com carbonato deformadas pela xistosidade $\mathrm{S}_{2}$. Nesta escala, $\mathrm{S}_{2}$ pode ser descrita como um bandamento onde se alternam bandas constituídas essencialmente por serpentina fina e bandas mais ou menos contínuas onde ocorrem os microlitons; resulta, desta forma, em um caráter levemente anastomosado para $\mathrm{S}_{2}$.

A serpentina recristalizada em $\mathrm{S}_{2}$ forma pequenas lamelas $(<0,3 \mathrm{~mm})$ de hábito hipidioblástico a idioblástico que sistematicamente truncam a serpentina ribbon e o carbonato que lhe é, por vezes, interdigitado. A intensa transposição das lamelas de serpentina ribbon dá origem a um entrelaçamento de lamelas finas, semelhante textura de superposição do tipo bladed-mat (Maltman 1978). O talco, quando presente, tem tamanho de 0,2-0,3 mm, ocorre nos microlitons e é trancado por serpentina $S_{2}$, ou recristaliza ao longo da xistosidade $S_{2}$; neste último caso, o talco manifesta contatos corrosivos com a serpentina ribbon.

A trama macroscópica para $\mathrm{K}_{1}$ varia entre um bandamento centimétrico a subcentimétrico, quando esta superfície está diretamente superimposta sobre a serpentina ribbon, e uma xistosidade onde a textura lepidoblástica aparece com mais nitidez. Porém, esta xistosidade ainda permite reconhecer alguns mesolitons decimétricos a métricos com intenso fraturamento interno de padrão losangular. Nas amostras do corpo de serpentinito CS2, o bandamento é mais facilmente identificado e pode ser descrito como a alternância de bandas com serpentina ribbon em microdobras e de bandas mais delgadas com textura lepidoblástica dada por serpentina fina, cristais idioblásticos de pinta (3-4 mm) e microlitons muito alongados da serpentina ribbon. A intensificação da xistosidade $\mathrm{K}_{1}$ generaliza a presença de microlitons e rompe os nódulos de carbonato com textura granoblástica para formar lentículas alongadas. A cristalização de serpentina fina ao longo da superfície $\mathrm{K}_{1}$ cria, novamente, um padrão de superposição do tipo entrelaçado, que pode ser genericamente descrito com o termo bladedmat de Maltman (1978).

Xistos magnesianos Os xistos magnesianos são as rochas metassomáticas concentricamente dispostas ao longo do contato entre a rocha ultramáfica e a rocha metassedimentar encaixante. Na região de Abadiânia (GO), estes xistos magnesianos se apresentam como zonas mono ou biminerálicas bem definidas, mas com espessura variável ao redor do núcleo serpentinítico. De acordo com o mineral predominante, foram individualizadas três zonas metassomáticas para efeito de des- 
crição petrográfica: 1 . a zona de talco, 2 . a zona de tremolita e 3. a zona de clorita.

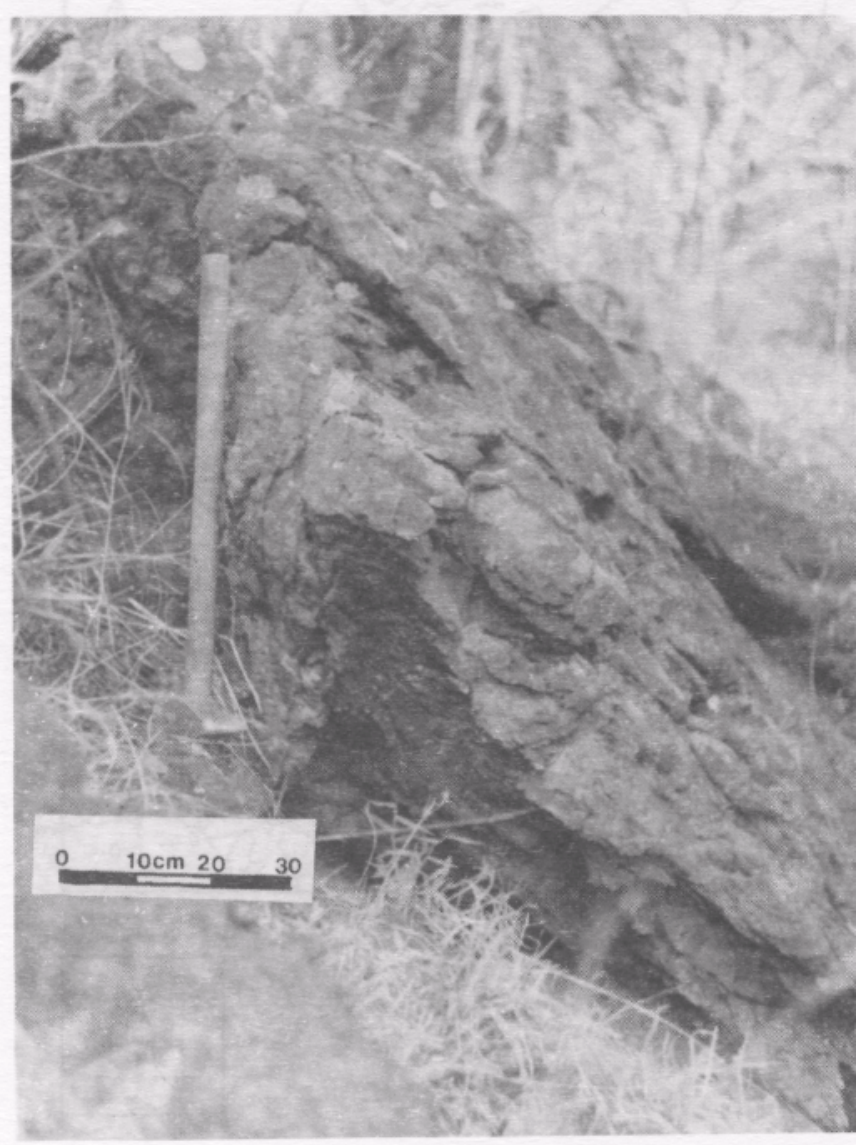

Foto 1 - Mesoliton de dobra $F_{2}$ em serpentinito do corpo CS7 Photo $1-\mathrm{F}_{2}$ fold mesolithon in the serpentinite body CS7

1. A zona metassomática de talco registra uma distinção petrográfica entre as xistosidades $\mathrm{S}_{1}$ e $\mathrm{S}_{2}$. A análise microscópica de um mesoliton revelou que a xistosidade $S_{1}$ era marcada por talco com granulação grossa $(0,6-2,5 \mathrm{~mm})$. O talco recristalizado ao longo de $S_{2}$ tem granulação bem mais fina (0,4-0,5 $\mathrm{mm}$ ) e mostra contatos corrosivos com o primeiro. De um modo geral, a xistosidade $\mathrm{S}_{2}$ constitui um bandamento marcado pela concentração de microlitons de talco+magnetita fina, de talco+carbonatcH-magnetita fina e de talco+clinocloro. A intensificação da deformação faz com que o bandamento evolua para uma xistosidade com textura lepidoblástica bem desenvolvida. A clorita presente na zona metassomática de talco é o clinocloro e ocorre em plaquetas espessas com tamanho entre 0,2 e $0,7 \mathrm{~mm}$ e está interdigitado com o talco em lentículas identificadas como microlitons. Os contatos cristalinos são de equilíbrio no interior dos microlitons, mas corrosivos entre os minerais dos microlitons e o talco recristalizado em $\mathrm{S}_{2}$.

A xistosidade $K_{1}$ do talco xisto possui uma textura lepidoblástica com raros microlitons de talco mais grosso e de orientação diversa daquele posicionado $\mathrm{em} \mathrm{K}_{1}$. $\mathrm{O}$ talco recristalizado ao longo de $\mathrm{K}_{1}$ ainda mais fino e manifesta contatos corrosivos com o talco presente nos microlitons.

A magnetita tem forma idioblástica $(0,4-0,6 \mathrm{~mm})$ ou xenoblástica alongada $(<0,2 \mathrm{~mm}) \mathrm{e}$, neste último caso, ocorre entre as lamelas de talco. O carbonato, por sua vez, tem forma hipidioblástica a idioblástica e tamanho que varia entre 0,1 e $1,0 \mathrm{~mm}$. Nas amostras em que o carbonato é a fase mineral principal e em que está concentrado em determinadas bandas, observa-se uma textura granoblástica.

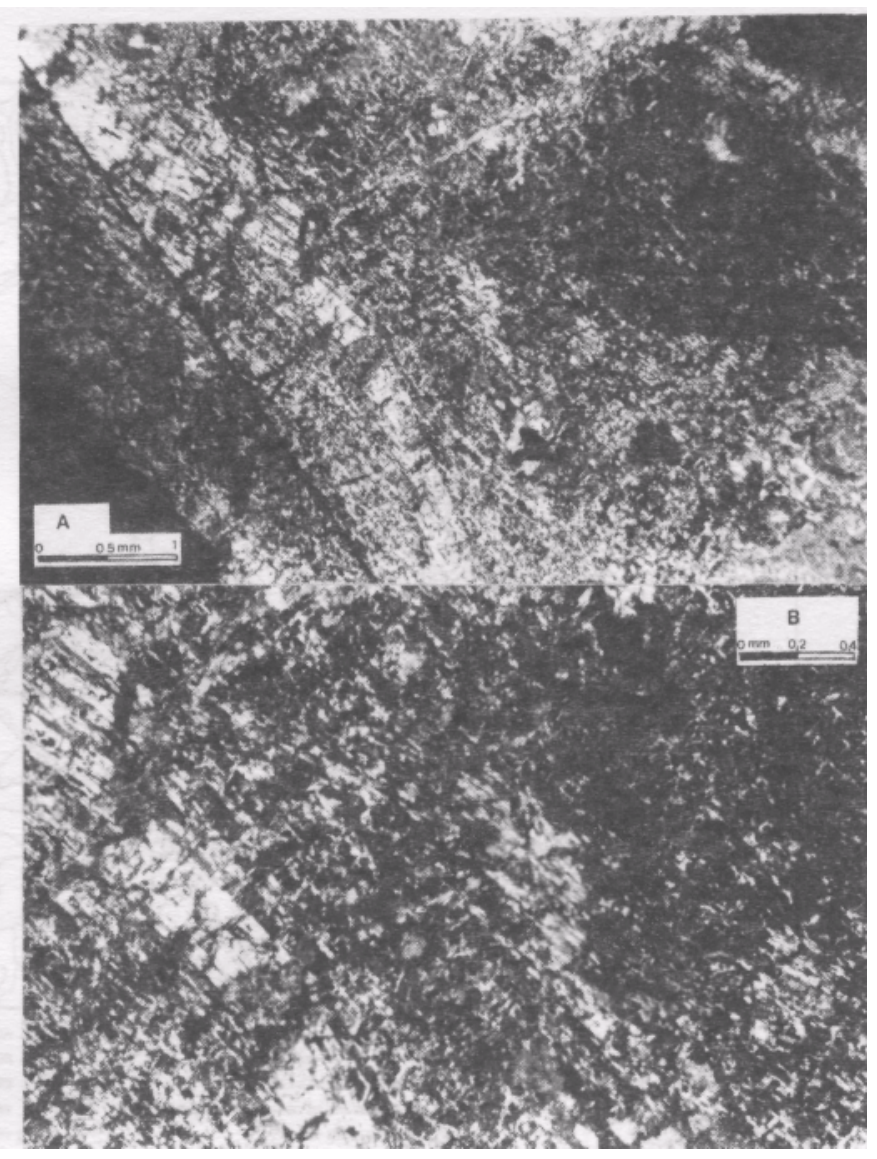

Foto 2 - Microliton de serpentina ribbon colocado ao longo da xistosidade $S_{2}$ e truncado por lamelas de serpentina que marcam a superficie $K_{1}$

Photo 2 - Ribbon serpentine microlithon placed in $\mathrm{S}_{2}$ foliation and truncated by small $\mathrm{K}_{1}$ surface serpentine flakes

2. A zona metassomática da tremolita foi identificada somente em alguns corpos de serpentinito e não parece ser contínua nos corpos onde ocorre. O clinocloro é normalmente observado como mineral constituinte e a sua quantidade parece aumentar significativamente com a proximidade da zona metassomática de clorita. A zona de tremolita apresenta uma textura S, que varia entre nematoblástica e lepidoblástica e que está crenulada em microdobras $\mathrm{F}_{2}$ de comprimento de onda sub-centimétrico; macroscopicamente, esta característica observada como uma espécie de bandamento. A tremolita cristalizada na xistosidade $\mathrm{S}_{1}$ tem hábito prismático curto a acicular e tamanho entre $0,3 \mathrm{e}$ $2,0 \mathrm{~mm}$; no entanto, a tremolita recristalizada ao longo de $\mathrm{S}_{2}$ tem dimensões inferiores a $0,8 \mathrm{~mm}$ e hábito acicular.

$\mathrm{O}$ clinocloro ocorre na forma de agregados semi-radiados com cristais individuais de tamanho entre 0,3 e $0,8 \mathrm{~mm}$, ou na forma de cristais finos que possuem $\pm 0,6 \mathrm{~mm}$ de tamanho e que estão colocados ao longo da foliação $\mathrm{S}_{2}$; os cristais finos de clinocloro truncam os agregados semi-radiados. Contatos corrosivos são identificados apenas entre a tremolita grossa de $S_{1}$ e o clinocloro recristalizado em $\mathrm{S}_{2}$. $\mathrm{O}$ carbonato aparece em quantidades secundárias e forma núcleos alongados segundo a xistosidade $\mathrm{S}_{1}$

3. A rocha da zona metassomática de clorita possui uma foliação $S_{2}$ cuja textura lepidoblástica não está completamente desenvolvida; embora as lamelas de clinocloro tenham uma orientação espacial predominante $\left(\mathrm{S}_{2}\right)$, a textura pode ser visualizada como um entrelaçamento de cristais e, portanto, pode ser descrita com o termo bladed-mat de Maltman (1978). Nos poucos locais onde a textura lepidoblástica da superfície $\mathrm{S}_{2}$ 
está evidente, pode-se observar lentículas com plaquetas de clinocloro que marcam a xistosidade $\mathrm{S}_{1}$ ou lentículas com textura granoblástica decussada a irregular (microlitons). Por outro lado, não se conseguiu separar adequadamente o clinocloro através do hábito e/ou tamanho em grupos que caracterizassem as xistosidades $\mathrm{S}_{1}$ e $\mathrm{S}_{2}$.

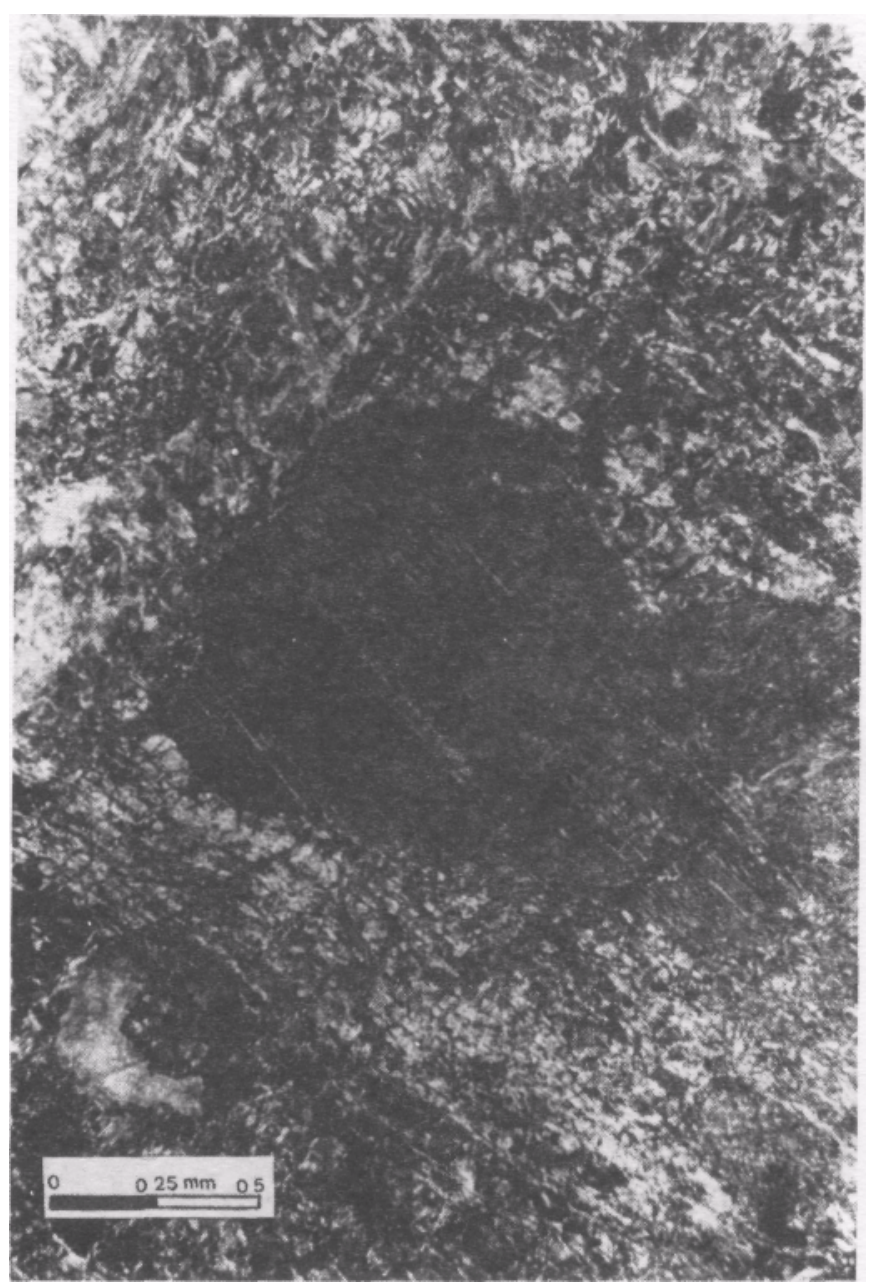

Foto 3 - Microlitons de serpentina ribbon e de enstalita alterada orientados ao longo da xistosidade $S_{2}$

Photo 3 - Ribbon serpentine and altered enstatite microlithons orientated in the $\mathrm{S}_{2}$ schistosity

A magnetita, que está sempre presente junto ao clinocloro, ocorre em cristais hipidioblásticos a idioblásticos com tamanho $<0,3 \mathrm{~mm}$ e, algumas vezes, dispostos ao longo da xistosidade $\mathrm{S}_{2}$.

A xistosidade $\mathrm{K}_{1}$ dos clorita xistos somente foi verificada no corpo de serpentinito CS4; neste local, a xistosidade marca um bandamento bem pronunciado que é dado pela concentração diferencial de agregados de magnetita muito fina (cloritamagnetita xisto bandado). As bandas com magnetita têm espessuras desde decimétrica até subcentimétrica e possuem caráter descontínuo. Em alguns casos, observa-se dobras sem raiz nas bandas de magnetita. A clorita é muito fina $(<0,2 \mathrm{~mm}) \mathrm{e}$ está fracamente superimposta e desenvolvida sobre remanescente de textura granoblástica formada por quartzo, feldspato (porfiroblastos de adularia) e granada.

DISCUSSÃO DAS OBSERVAÇÕES PETROGRÁFICAS O metamorfismo e o metassomatismo sobre os corpos de serpentinito resultaram no desenvolvimento de cinco diferentes paragêneses metamórfico-metassomáticas que são recorrentes em cada fase deformacional. Observou-se que os contatos cristalinos entre fases minerais idênticas, mas relacionadas a diferentes fases deformacionais, são, em muitos casos, contatos retilíneos de equilíbrio; de outro modo, os contatos entre fases minerais distintas posicionadas em diferentes superfícies deformacionais, são predominantemente corrosivos.

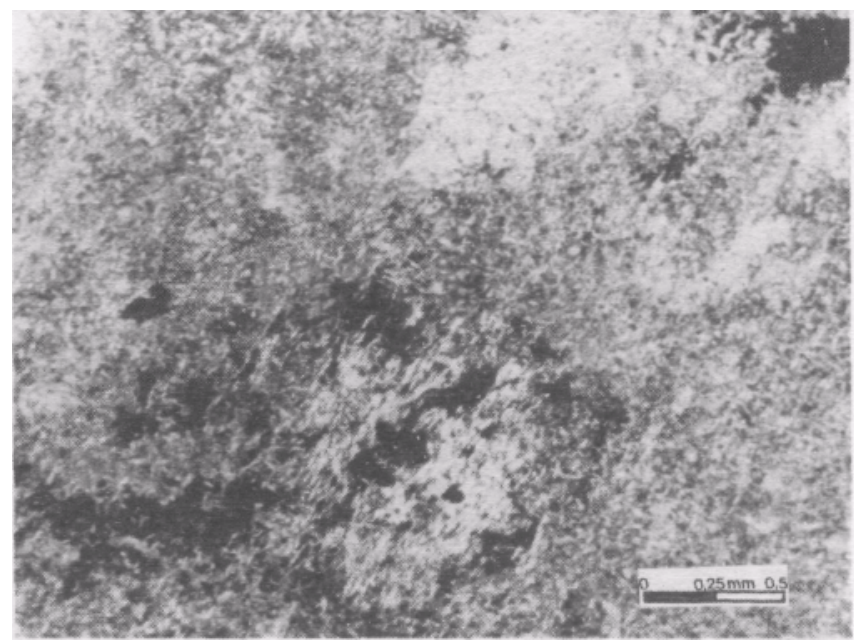

Foto 4 - Textura bladed-mat originada pela superposição de lamelas de serpentina que marcam as xistosidades $S_{2}$ e $K_{1}$. Núcleos arredondados de serpentina, cercados por magnetita, podem representar pseudomorfos de olivina Photo 4 - Bladed-mat texture formed by the superposition of $\mathrm{S}_{2}$ and $\mathrm{K}_{1}$ foliation serpentine flakes. Round nuclei of serpentine enveloped by magnetite may represents olivine pseudomorphs

Em termos petrológicos, pode ser importante investigar as modificações na estrutura cristalina das serpentinas para avaliar as condições gerais do processo de serpentinização (Wicks \& Whittaker 1977). Neste sentido, as várias formas texturais de serpentina (enstatita alterada, ribbon, bladed-mat) foram individualmente analisadas sob difratometria de raios-X (Fig. 2); isto permitiu identificar a antigorita $6 \mathrm{M}$ como o polimorfo estável de serpentina durante todo o processo metamórficodeformacional registrado na área. A análise difratométrica em várias amostras permitiu identificar, ainda, a recristalização de talco-clorita a partir de serpentina, e de clinocloro sobre os minerais que compõe a rocha encaixante dos corpos de serpentinito (Fig. 2D, E).

A não ser pelas poucas evidências de pseudomorfos, os serpentinitos apresentam uma trama metamórfico-deformacional totalmente desenvolvida. Assim, qualquer análise da relação temporal entre a serpentinização e a deformação é restringida ao registro da trama $S_{1}$, que já indica a completa serpentinização não-pseudomórfica dos corpos ultramáficos e a estabilização da antigorita como polimorfo de serpentina. Estas características permitem classificar o processo de serpentinização como do Tipo 7 descrito por Wicks \& Whittaker (1977).

A análise do significado petrológico das texturas geradas em serpentinitos durante as várias fases deformacionais não tem recebido maior atenção na literatura. Porém, o tratamento dado à confecção das lâminas delgadas dos corpos de serpentinito de Abadiânia permite o reconhecimento dos tipos texturais descritos por Maltman (1978). Conforme a caracterização petrográfica das superfícies deformacionais de cada tipo litológico da região (Strieder 1989), a textura ribbon é relacionada a uma fase de intensa milonitização regional $\left(\mathrm{D}_{1}\right)$. Devido à sua intensidade, as superposições de $\mathrm{S}_{2}$ e $\mathrm{K}_{1}$ estão claramente 
impressas nos corpos de serpentinito através da recristalização da serpentina fina e resultam, desta forma, no desenvolvimento de texturas bladed-mat.

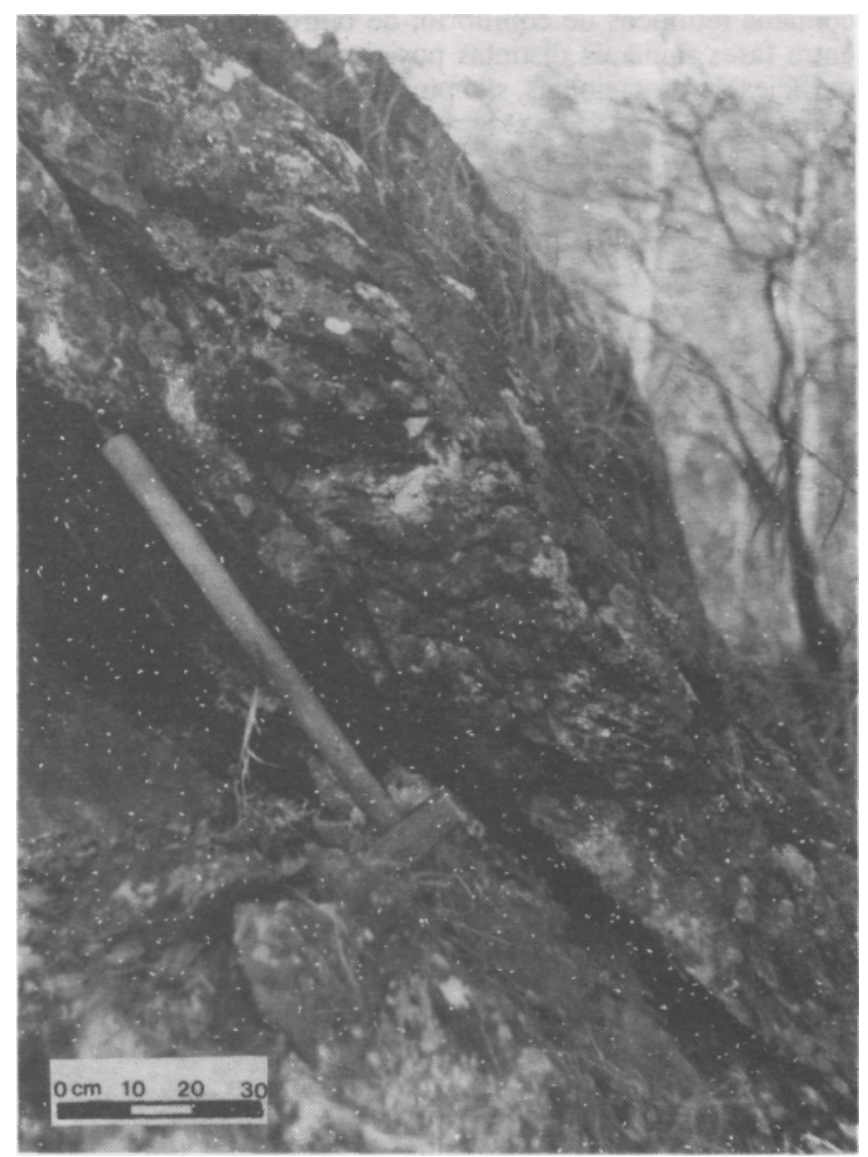

Foto 5 - Mesoliton de crenulação tipo cisalha em serpentinito do corpo CS7

Photo 5 - Shear type crenulation in a $\mathrm{D}_{2}$ mesolithon structure of the serpentinite Body CS7

Da mesma forma que o serpentinito, a zonação metassomática estabelecida ao redor dos corpos ultramáficos registra apenas os efeitos texturais gerados a partir da primeira fase deformacional e, com isso, pode-se indicar apenas que a serpentinização e o metassomatismo ocorreram junto com o desenvolvimento de $\mathrm{S}_{1}$.

A correlação alcançada entre as características das superfícies deformacionais nos vários litotipos descritos na região exige que as suas paragêneses metamórficas estejam perfeitamente correlacionadas dentro de um certo intervalo de $\mathrm{P}$ e T. O limite inferior de temperatura é dado pelas reacões que eliminam a clorita das paragêneses félsicas e máficas e o limite superior, pelas reações de formação da cordierita e da estaurolita em metassedimentos ricos em álcalis e a condições de alta $\mathrm{f}_{02}$ (Fig. 3). Este campo de estabilidade delimita paragêneses de fácies anfibolito baixo.

A inexistência de forsterita metamórfica nestas condições pode ser explicada pela baixa relação $\mathrm{MgO}+\mathrm{FeO} /$ $\mathrm{MgO}+\mathrm{FeO}+\mathrm{SiO}_{2}$ dos serpentinitos (situada entre 0,4 e 0,5 ); sob estas condições químicas, a paragênese antigorita+talco é estável desde as temperaturas mais baixas do metamorfismo e não é possível o aparecimento da brucita (Trommsdorff \& Evans 1974). Portanto, a reação que marca o primeiro aparecimento da forsterita metamórfica a partir da antigorita (reação 5, Fig. 3) também pode ser utilizada como o limite superior para a temperatura de metamorfismo alcançada na região.

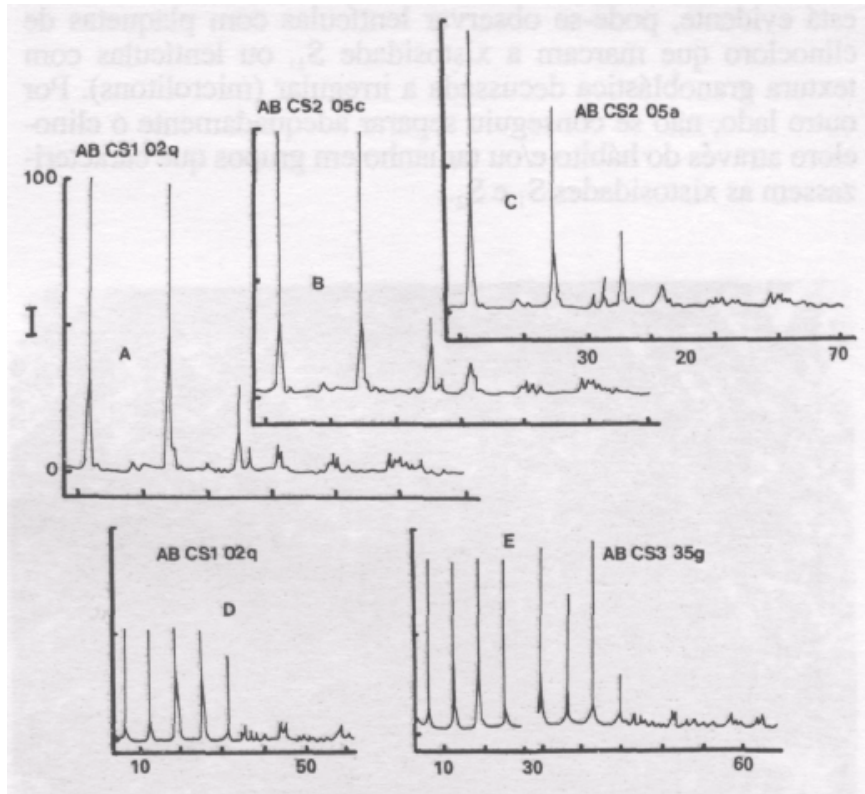

Figura 2 - Difratogramas de raios $X$ de serpentina $(\boldsymbol{A})$ ribbon, (B) enstatita alterada e (C) bladed-mat, de (D) talco-clorita e de $(\boldsymbol{E})$ clinocloro

Figure 2 - Difratograms of: (A) Ribbon, (B) altered enstatite and (C) blade-mat serpentines, (D) talc-chlorite and (E) clinochlore

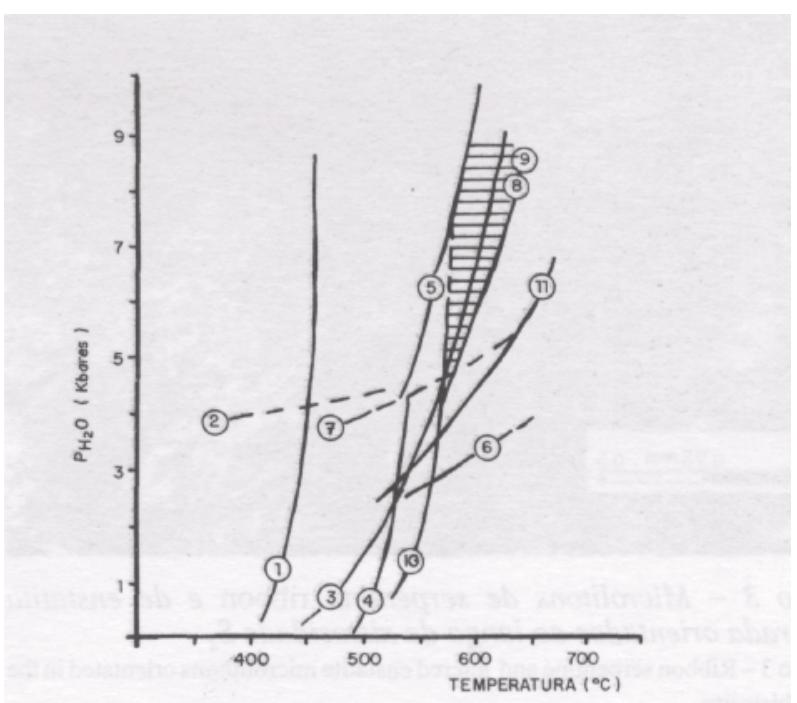

1 - Estilpnomelano + muscovita + actionolita $\rightarrow$ biotita + clorita $+\mathrm{H}_{2} \mathrm{O}$ estilpnomelana + muscovita $\rightarrow$ biotita + clorita + quartzo $+\mathrm{H}_{2} \mathrm{O}$ (In: Winkler 1978) 2. - Delimita o campo de estabilidade do cloritóide

3. - Antigorita $\rightarrow$ forsterita + talco $+\mathrm{H}_{2} \mathrm{O}$ (In: Evans 1977)

4. - Clorita + muscovita + quartzo $->$ cordierita + biotita $+\mathrm{Al}_{2} \mathrm{SiO}_{3}+\mathrm{H}_{2} \mathrm{O}$ (Winkler 1978) 5. - Cloritóide $+\mathrm{O}_{2} \rightarrow$ estaurolita + magnetita + quartzo $+\mathrm{H}_{2} \mathrm{O}$ (Ganguly 1968 e 1972) 6. - Estaurolita + quartzo $\rightarrow$ cordierita com $\mathrm{Fe}+$ silimanita $+\mathrm{H}_{2} \mathrm{O}$ (Ganguly 1968)

7. - Cromita com $\mathrm{Fe}+$ muscovita + quartzo $\rightarrow$ almandina + biotita $+\mathrm{Al}_{2} \mathrm{SiO}_{5}+\mathrm{H}_{2} \mathrm{O}$ (In:Wrinkler1978)

8. - Cloritóide + quartzo $\rightarrow$ estaurolita + almandina $+\mathrm{H}_{2} \mathrm{O}$ (Ganguly 1969)

9. - Almandina $+\mathrm{H}_{2} \mathrm{O}+\mathrm{O}_{2} \rightarrow$ estaurolita + magnetita + quartzo (Ganguly 1972)

10. - Clorita + ti tanita + quartzo $\rightarrow$ anfibólio com $\mathrm{Al}+$ ilmenita $-\mathrm{f}_{2} \mathrm{O}$ (Liou et al 1974)

11. - Epídoto + quartzo $\rightarrow$ anortita + grossulária + magnetita $+\mathrm{H}_{2} \mathrm{O}$ (Liou 1973)

Figura 3 - Diagrama PxT que apresenta os limites de estabilidade das paragêneses metamórficas na região de Abadiânia $(G O)$. A reação 1 representa o limite inferior aproximado do fácies xistos verdes

Figure 3 - PxT diagram showing the stability boundaries of the Abadiânia region (GO) metamorphic paragenesis. Reaction 1 are the approximate inferior boundary of the green schist facies 
Sobre a discussão inicial do metassomatismo, vários autores (Evans 1977, Brady 1977, Sanford 1982) têm ressaltado uma ligação entre a zonação metassomática estabelecida em corpos de serpentinito e as condições de temperatura do metamorfismo regional; estes trabalhos, por exemplo, relacionam a existência de uma zona com tremolita/actinolita a condições de temperatura equivalente à transição entre o metamorfismo de baixo grau (fácies xistos verdes) e de médio grau (fácies epidotoanfibolito). Assim, a identificação de tal zona metassomática nos corpos de serpentinito de Abadiânia permite situar estes corpos nas condições metamórficas previstas acima.

\section{CARACTERIZAÇÃO PETROQUÍMICA DOS CORPOS}

Uma vez que o metamorfismo exerce uma forte influência na modificação de alguns parâmetros químicos relacionados aos corpos de serpentinito, faz-se necessária uma análise dos resultados desta influência para fixar as condições sob as quais as modificações podem ter ocorrido e para avaliar a extensão destas modificações. Assim, este capítulo foi estruturado para, inicialmente, isolar e avaliar quimicameníe as modificações decorrentes do metamorfismo e do metassomatismo sobre os corpos de serpentinitos e, posteriormente, proceder ao tratamento petroquímico mais apurado destas rochas, no sentido de definir a afinidade geoquímica do seu protolito.

\section{Metassomatismo dos corpos de serpentinito}

estudo dos processos metassomáticos ao longo dos bordos dos corpos ultramáficos está ligado à avaliação da extensão das modificações químicas introduzidas como resultado da interação destes corpos com rochas encaixantes de composição química fortemente contrastante. Este estudo tem servido para investigar a mobilidade de determinados componentes químicos e para traçar considerações acerca das condições químicas em que se processaram o metassomatismo e a serpentinização.

A metodologia de investigação do metassomatismo utilizada neste artigo é discutida por Strieder (1992). Este artigo pretende mostrar, então, a utilização prática dos critérios que foram teoricamente expressos.

A primeira questão diz respeito ao mecanismo de transferência de massa predominante, responsável pela zonação metassomática. A quantidade extremamente pequena de veios de crisotila, a ausência de veios de outra natureza e a definição de zonas metassomáticas concentricamente dispostas com relação aos núcleos serpentiníticos permitem caracterizar a difusão intergranular como o principal mecanismo de transferência de massa; estas características sugerem, também, que a transferência de massa ocorreu sob condições restritas de $a_{2} \mathrm{O}$ e num ambiente fechado à livre circulação de material. Sob tais condições, a investigação das modificações químicas é mais fácil na medida em que as precauções de amostragem podem ser reduzidas à utilização de amostras suficientemente distantes de pequenos veios de crisotila e à definição da distância com relação ao bordo do corpo de serpentinito. No entanto, no caso dos corpos de serpentinito de Abadiânia, houve uma grande dificuldade de se obter, sistematicamente, amostras frescas ao longo de uma seção única das zonas metassomáticas de cada corpo; este fato certamente responsável por uma parte da dispersão dos parâmetros químicos discutidos a seguir.

Trocas metassomáticas entre elementos maiores e menores $\mathrm{O}$ primeiro ponto a ser definido nesta avaliação é o contato inicial entre o corpo ultramáfíco e a sua encaixante. Neste sentido, o diagrama triangular AMS (Fig. 4) permite verificar 1. que o conteúdo de $\mathrm{Al}_{2} \mathrm{O}_{3}+\mathrm{Fe}_{2} \mathrm{O}_{3}$ é mantido quando são relacionadas as zonas metassomáticas e as rochas das quais derivam e 2. que as trocas químicas ocorreram significativamente entre os componentes $\mathrm{MgO}$ e $\mathrm{SiO}_{2}$. O contato inicial, então, pode ser distinguido por esta representação gráfica: ele está localizado entre as zonas de talco e de clorita e é materializado pela zona de clinocloro+tremolita.

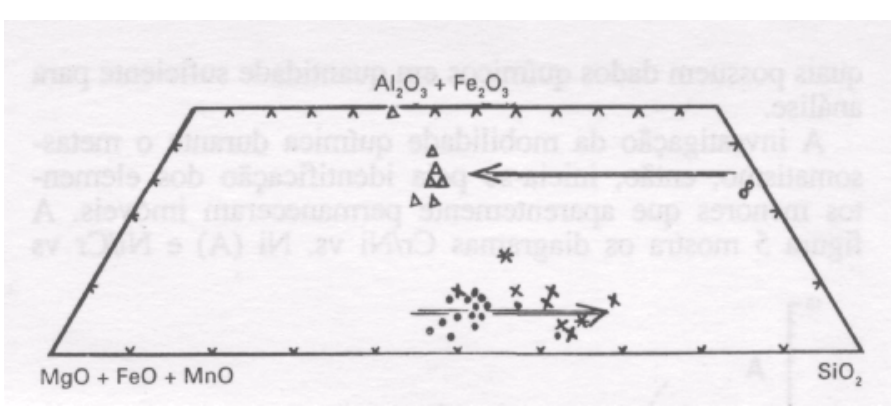

Figura 4 - Diagrama AMS que relaciona a composição química global das zonas metassomáticas com a composição química das rochas originais. - serpentinitos, $x$ talco xisto, ${ }^{*}$ cloritatremolita xisto, A clorita xisto, O granada-mica-quartzo xisto Figure 4 - AMS diagram relating the whole chemical composition of the metasomatic zones and the chemical composition of the original rocks. - serpentinites, $\mathrm{x}$ talc xist, ${ }^{*}$ chlorite-tremolite schist, A chlorite schist, $\mathrm{O}$ gametmica-quartz schist

Para avaliar a mobilidade dos elementos químicos sob difusão intergranular foi realizada uma série de construções gráficas de acordo com a metodologia discutida por Strieder (1992). Aquele método de análise permite distinguir as amostras que apresentam um comportamento geoquímico pouco consistente, o qual pode ser encarado como resultado da modificação na sua proporção relativa dos elementos durante o processo de serpentinização e de metassomatismo de bordo. Nos diagramas que serão apresentados, as amostras cuja proporção relativa dos elementos foge do trend normal estão assinaladas e, como se verifica, são as mesmas em todos os diagramas. Estas amostras, posteriormente, não serão utilizadas nas investigações da natureza petroquímica do protolito dos serpentinitos.

A análise inicial dos diagramas revelou uma dispersão importante para as amostras de clorita xisto e de granada-micaquartzo xisto. Esta dispersão reflete variações na composição química e mineralógica da rocha encaixante original e variações no desenvolvimento da transferência bilateral de massa. De um modo geral, o granada-mica-quartzo xisto mostra variações nas proporções relativas de $\mathrm{Al}_{2} \mathrm{O}_{3}+\mathrm{K}_{2} \mathrm{O} / \mathrm{Na}_{2} \mathrm{O}+\mathrm{CaO}$ e de $\mathrm{Al}_{2} \mathrm{O}_{3}+\mathrm{FeO} *+\mathrm{MgO} / \mathrm{SiO}_{2}+\mathrm{Na}_{2} \mathrm{O}+\mathrm{CaO}$, as quais podem corresponder às variações mineralógicas dadas principalmente por feldspatos + moscovitas e por feldspatos+biotita+granada Estas variações composicionais/mineralógicas parecem estar refletindo o bandamento milimétrico metamórfico das rochas metassedimentares; a presença de zonas com maior conteúdo de feldspato + moscovita, ou de mica + anfibólio + granada (Strieder 1989), pode estar refletindo variações composicionais de maior escala que foram transpostas pela deformação e pelo metamorfismo. O clorita xisto, de outro modo, apresenta variações significativas de $\mathrm{SiO}_{2}, \mathrm{Al}_{2} \mathrm{O}_{3}, \mathrm{MgO}$ e do $\mathrm{FeO}^{*}$; isso corresponde às variações composicionais da clorita, mas, principalmente, às variações na proporção entre clorita e magnetita. A amostra CS3-35G mostra uma forte diminuição do $\mathrm{MgO}$ e um aumento de $\mathrm{FeO}^{*}$ e de $\mathrm{Al}_{2} \mathrm{O}_{3}$, a qual parece corresponder às amostras mais ricas em magnetita; isto é confirmado na amostra CS4-72L, que possui uma predominância muito acentuada de magnetita sobre a clorita e forma um clorita + magnetita xisto bandado. Este comportamento parece indicar que, em certos locais, houve uma concentração acentuada do $\mathrm{FeO}^{*}$ em conseqüência da diminuição do volume da rocha encaixante metassomatizada, de modo a formar uma zona metassomática distinta.

Deste modo, na análise dos diagramas para o metassomatismo, são comumente desconsiderados alguns termos composicionais limites (amostras AB-32, CS3-35G e CS4-72L). Este procedimento permite comparar as modificações químicas introduzidas em uma rocha original predominantemente formada por granada+feldspatos + micas + quartzo para formar uma paragênese metassomática do tipo magnetita+clorita, as 
quais possuem dados químicos em quantidade suficiente para análise.

A investigação da mobilidade química durante o metassomatismo, então, inicia-se pela identificação dos elementos menores que aparentemente permaneceram imóveis. A figura 5 mostra os diagramas $\mathrm{Cr} / \mathrm{Ni}$ vs. $\mathrm{Ni}$ (A) e $\mathrm{Ni} / \mathrm{Cr}$ vs
$\mathrm{Cr}$ (B), onde é possível distinguir os trends químicos das rochas originais e das respectivas zonas metassomáticas; com exceção das amostras assinaladas, pode-se perceber, em maior ou em menor grau, o paralelismo e a proximidade dos trends de granada-mica-quartzo xisto e de clorita xisto e dos trends de serpentinito e de talco xisto. Este caráter sugere que a grande
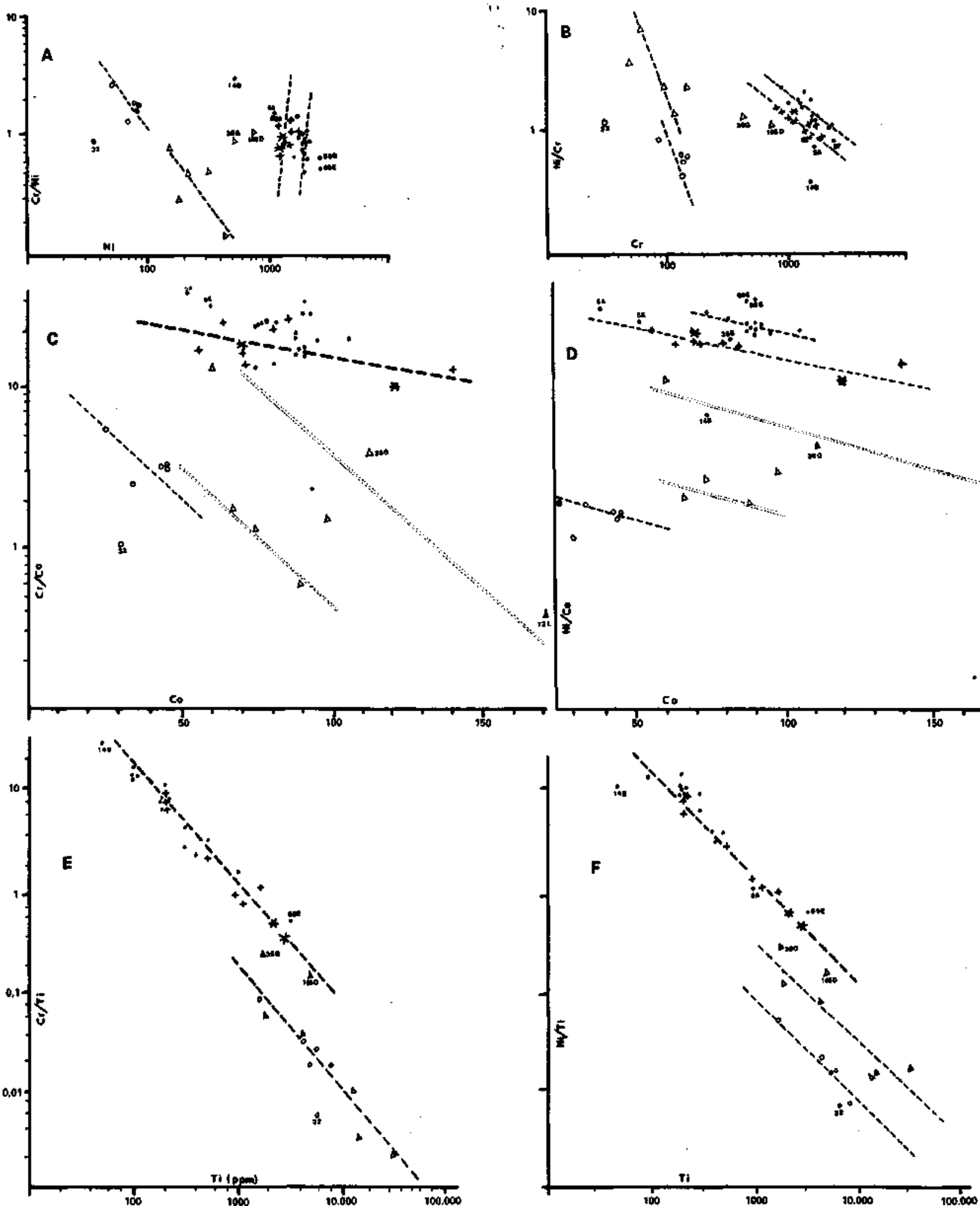

Figura 5 - Diagramas (A) Cr/Nix Ni, (B) Ni/Cr x Cr, (C) Cr/Co x Co, (D) Ni/Co x Co, (E) Cr/Tix Ti e (F) Ni/Tix Ti que mostram a modificação do conteúdo relativo dos elementos entre as zonas metassomáticas. Símbolos como na figura 4

Figure 5 - Diagrams showing the change of the relative amount of elements between the metasomatíc zones: (A) $\mathrm{Cr} / \mathrm{Ni}$ x Ni, (B) $\mathrm{Ni} / \mathrm{Cr} \times \mathrm{Cr}$, (C) $\mathrm{Cr} / \mathrm{Co} x$. Co, (D) Ni/ $\mathrm{Co} \times \mathrm{Co},(\mathrm{E}) \mathrm{Cr} / \mathrm{n} \times \mathrm{Ti}$ and $(\mathrm{F}) \mathrm{Ni} / \mathrm{Ti} \times \mathrm{Ti}$. The symbols are the same as figure 4 
parte das amostras não modificou a proporção relativa entre $\mathrm{Cr}^{3+} \mathrm{e} \mathrm{Ni}^{2+}$. O afastamento dos pares de trend mostra que houve um aumento de volume na Zona de talco e uma diminuição de volume na zona de clorita com a conseqüente diluição e concentração destes elementos imóveis nas respectivas zonas metassomáticas.

A observação das figuras $5 \mathrm{C}$-F mostra que os trends químicos traçados para a proporção relativa entre $\mathrm{Cr}-\mathrm{Co}, \mathrm{Ni}-\mathrm{Co}, \mathrm{Gr}-$ Ti e Ni-Ti, embora pequenos desajustes locais, têm o mesmo comportamento geral daquele observado para o $\mathrm{Cr}-\mathrm{Ni}$. As figuras 5C-D mostram uma dispersão significativa para as análises de clorita xisto, o que não permite traçar, com clareza, trends de variação química para as razões $\mathrm{Cr} / \mathrm{Co}$ vs. $\mathrm{Co}$ e $\mathrm{Ni} / \mathrm{Co}$ vs. Co. De qualquer modo, se o Co for considerado como elemento imóvel, como parecem demonstrar os trends para talco xisto e para serpentinito, pode-se traçar uma faixa de variação química cujo bordo superior é definido pelas amostras CS3-35G, CS4-72L e CS9-105D; as duas primeiras amostras estão mais fortemente enriquecidas em magnetita e, pelo seu posicionamento em ambos os gráficos, representam as porções onde a redução de volume por conta do metassomatismo foi mais forte. Esta faixa de variação química é delimitada por linhas pontilhadas nas figuras 5C-D.

A avaliação da mobilidade química através dos elementos menores mostrou que, de um modo geral, $\mathrm{Ni}^{2+}, \mathrm{Cr}^{3+}, \mathrm{Co}^{2+}$ e $\mathrm{Ti}^{-4+}$ foram essencialmente imóveis durante o metassomatismo. Desta forma, pode-se utilizá-los como "marcadores inertes" para avaliar o sentido da transferência de massa desenvolvida com relação aos elementos maiores. Para fazer esta avaliação, a composição química das amostras foi recalculada para percentagem de peso atômico anidro (\% p.at).

A figura 6 apresenta os diagramas $\mathrm{Cr} / \mathrm{Si}$ vs. $\mathrm{Si}(\mathrm{A})$ e Ni/Si vs. $\mathrm{Si}(B)$ e ilustra, de forma muito particular, como pode ser interpretada a mudança na proporção relativa dos elementos maiores. O comportamento distinto dos trends de serpentinito e de talco xisto indicam que houve um aumento de volume e de conteúdo de $\mathrm{Si}^{4+}$ na zona metassomática de talco, porque o trend do talco xisto está posicionado em valores mais altos de $\mathrm{Si}^{4+}$ e em valores mais baixos de razão $\mathrm{Cr} / \mathrm{Si}$ e porque foi "rotacionado" no sentido anti-horário com relação ao trend dos serpentinitos. $\mathrm{O}$ aumento de conteúdo de $\mathrm{Si}^{4+}$ na zona de talco foi acompanhado de uma diminuição no conteúdo do $\mathrm{Si}^{4+}$ na rocha encaixante, porque se observa que o trend do clorita xisto, com relação ao granada-mica-quartzo xisto, tem um comportamento exatamente inverso daquele do talco xisto com relação ao serpentinito.

O mesmo sentido de troca metassomática pode ser observado nas figuras $6 \mathrm{C}-\mathrm{D}$ com relação ao $\mathrm{Al}^{3+}$; contudo, a interpreta-

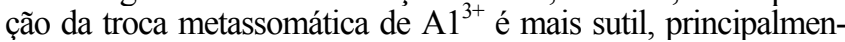
te para o clorita xisto e para o granada-mica-quartzo xisto, porque 1. a quantidade de transferência de massa envolvida foi pequena e porque 2 . a dispersão das análises de clorita xisto não permite traçar um trend claro de variação química. A pequena transferência de $\mathrm{Al}^{3+}$, como pode ser percebido pela diferença de inclinação dos trends de serpentinito e de talco xisto, parece estar de acordo com a temperatura metamórfica em que este metassomatismo ocorreu, pois o $\mathrm{Al}^{3+}$ somente ganha mobilidade metassomática somente a partir de condições metamórficas equivalentes a fácies xisto verde superior (Strieder 1992).

Os diagramas $\mathrm{Cr} / \mathrm{Mg}$ vs. $\mathrm{Mg}$ e Ni/Mg vs. $\mathrm{Mg}$ (Fig. 6E-F) são muito importantes, porque confirmam a transferência bilateral de massa, na medida em que o comportamento relativo dos trends dos serpentinitos, dos talco xistos, dos granada-mica-quartzo xistos e dos clorita xistos é inverso ao comportamento observado nos diagramas anteriores. Ou seja, há uma transferência de $\mathrm{Mg}^{2+}$ dos serpentinitos para o granada-mica-quartzo xisto encaixante, concordante com o gradiente químico desenvolvido no contato entre estes dois tipos litológicos.
As figuras 6G-H analisam o comportamento químico do $\mathrm{Fe}^{*}$ com relação ao $\mathrm{Cr}$ e ao $\mathrm{Ni}$. A dispersão das análises de clorita xisto, principalmente, define uma faixa de variação composicional, cujo limite superior é novamente dado pelas amostras com alto conteúdo de magnetita (CS3-35G e CS4-72L). A dispersão destas análises, porém, é acentuada pela forte diminuição de volume da zona metassomática de clorita (ou de magnetita!). De qualquer modo, estas figuras parecem indicar que não houve troca metassomática de $\mathrm{Fe}^{*}$. Como pode ser observado na tabela 1 , a amplitude de variação e o conteúdo médio do $\mathrm{FeO}^{*}$ dos serpentinitos eqüivale àquela dos granada-mica-quartzo xistos e, portanto, o gradiente químico necessário à transferência de $\mathrm{Fe}^{*}$ pode não ter sido gerado nos primeiros estágios de serpentinização. Entretanto, com o avanço do metassomatismo e a contínua diminuição do volume da zona metassomática de clorita, há um aumento na concentração de $\mathrm{FeO}^{*}$ e, a partir daí, pode haver uma transferência de $\mathrm{Fe}^{*}$ em direção aos talco xistos.

A análise qualitativa do metassomatismo estabelecido entre os serpentinitos e o granada-mica-quartzo xisto encaixante mostrou que $\mathrm{Ni}^{2+}, \mathrm{Cr}^{3+}, \mathrm{Co}^{2+}, \mathrm{Ti}^{4+}$ e $\mathrm{Fe}^{*}$ foram elementos imóveis durante a transferência de $\mathrm{Si}^{4+}$ e de $\mathrm{Al}^{3+}$ em direção ao serpentinito e de $\mathrm{Mg}^{2+}$ em direção ao granada-mica-quartzo xisto. Já que a serpentinização e o metassomatismo são partes de um mesmo e contínuo processo de reequilíbrio metamórfico das rochas ultramáficas originais (serpentinização do tipo 7 de Wicks \& Whittaker 1977), estes resultados mostram a necessidade de se ter cuidado na utilização das análises químicas de serpentinito para fins petroquímicos, porque elas podem estar enriquecidas em $\mathrm{SiO}_{2}$ e em $\mathrm{Al}_{2} \mathrm{O}_{3}$ e empobrecidas em $\mathrm{MgO}$. Neste sentido, as amostras de serpentinito que se apresentam dispersas com relação ao trend médio não serão utilizadas na investigação petroquímica do protolito dos serpentinitos; parece importante Observar, ainda, que as amostras que se dispersam com relação ao trend médio são praticamente as mesmas em todos os diagramas: CS1-02M, CS2-05B, CS2-05F, e AL-14B. Neste ponto, é necessário deixar claro que foi a análise conjunta dos diagramas que forneceu uma resposta aproximada ao problema da transferência metassomática de massa. Cada diagrama enfatiza aspectos composicionais particulares de zonas metassomáticas específicas e, por isso, há a necessidade de avaliá-los todos em conjunto. Este método de avaliação das trocas metassomátieas deve ainda ser testado em um perfil único de metassomatismo, mas, contudo, já demonstra a sua funcionalidade.

Trocas metassomáticas de Elementos Terras Raras A extensão das trocas químicas ocorridas durante o metassomatismo de bordo dos corpos de serpentinito também pode ser avaliada através do uso de padrões de Elementos Terras Raras (ETR, Fig. 7). O uso destes padrões com tal finalidade tem sido reduzido; porém, pode-se fazer uma comparação com os dados de Fowler et al (1983), apesar do metamorfismo um pouco mais elevado (fácies anfibolito) sofrido pelas rochas investigadas por aqueles autores. Os resultados fornecidos na figura 7 confirmam a derivação da zona metassomática de clorita a partir da rocha encaixante; porém, embora esta apresente um padrão ETR muito semelhante àquele de sedimentos fluviais (Humphris 1984), uma avaliação da extensão da modificação no padrão ETR da rocha encaixante não é possível, porque não se dispõe de análises para tal fim. Por outro modo, o padrão ETR para a zona metassomática de talco revela um significativo aumento no conteúdo de ETRL; este conteúdo diminui gradativamente até o $\mathrm{Lu}$, onde nenhuma mudança é observada com relação ao conteúdo apresentado pelos serpentinitos. Os padrões ETRP das zonas de talco e de clorita, por serem aproximadamente paralelos, refletem a forte interação química das rochas reagentes e indicam que o desenvolvimento da zona metassomática de talco, como conseqüência da significativa introdução de $\mathrm{SiO}_{2}$, é acompanhado da introdução dos ETR. 

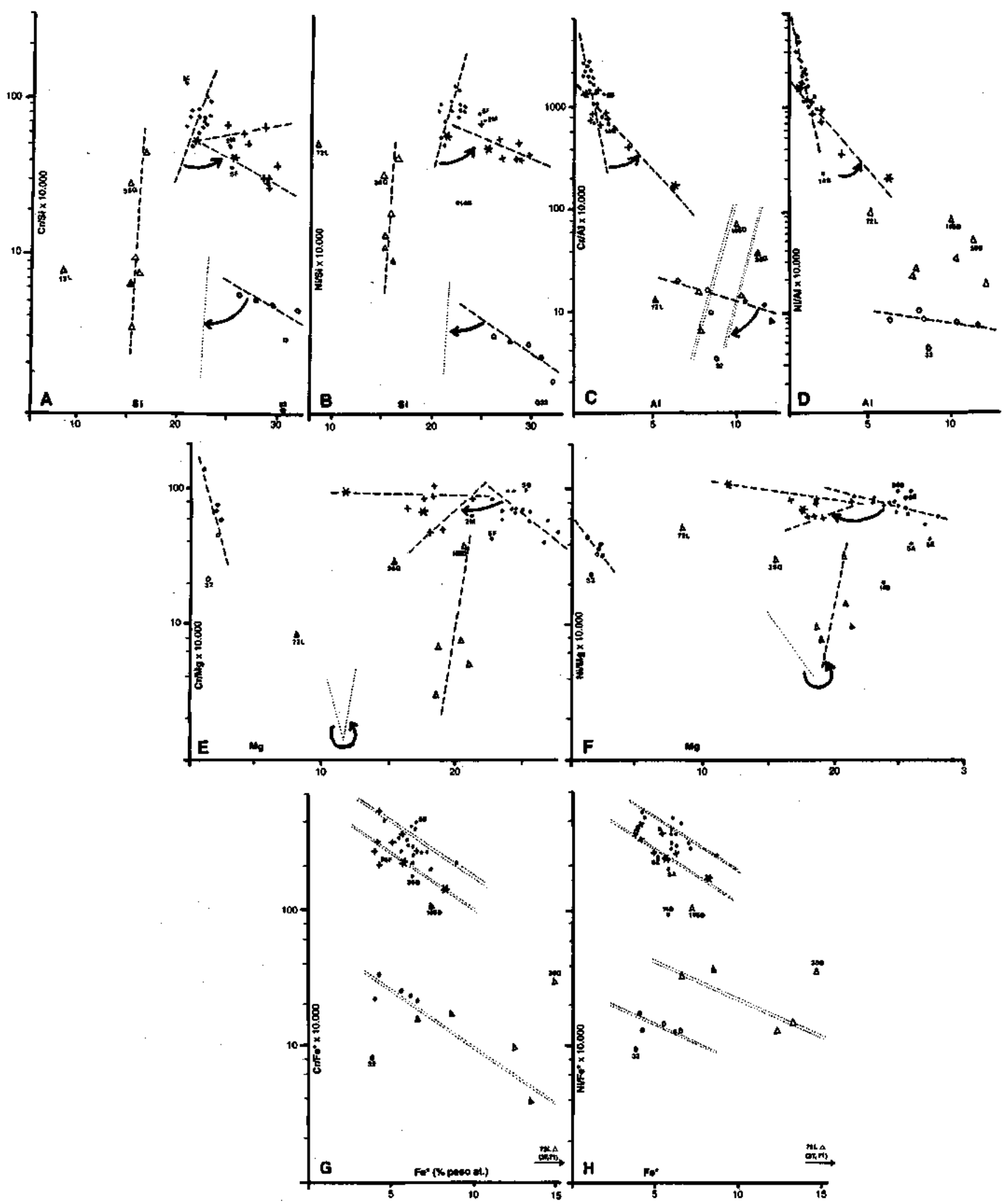

Figura 6 - Diagramas (A) Cr/Si $x \mathrm{Si}$, (B) Ni/Si $x \mathrm{Si}$, (C) Cr/Al $x \mathrm{Al}$, (D) Ni/Al $x \mathrm{Al}$, (E) $\mathrm{Cr} / \mathrm{Mg} \times \mathrm{Mg}$, (F) $\mathrm{Ni} / \mathrm{Mg} \times \mathrm{Mg}$, (G) $\mathrm{Cr} / \mathrm{Fe}$ * $x$ $\mathrm{Fe}^{*}$ e (H) $\mathrm{Ni} / \mathrm{Fe}^{*} \times \mathrm{Fe}^{*}$ que mostram a modificação do conteúdo entre os elementos nas zonas metassomáticas. Símbolos como na figura 4

Figure 6 - Diagrams showing the global element changes in the metasomatic zones: (A) $\mathrm{Cr} / \mathrm{Si}$ x Si, (B) Ni/Si x Si, (C) $\mathrm{Cr} / \mathrm{Al}$ x Al, (D) Ni/Al x Al, (E) $\mathrm{Cr} / \mathrm{Mg}$ x Mg, (F) $\mathrm{Ni} / \mathrm{Mg} \times \mathrm{Mg},(\mathrm{G}) \mathrm{Cr} / \mathrm{Fe}^{*} \times \mathrm{Fe}^{*}$ and $(\mathrm{H}) \mathrm{Ni} / \mathrm{Fe}^{*} \times \mathrm{Fe}^{*}$. The symbols are the same as figure 4 


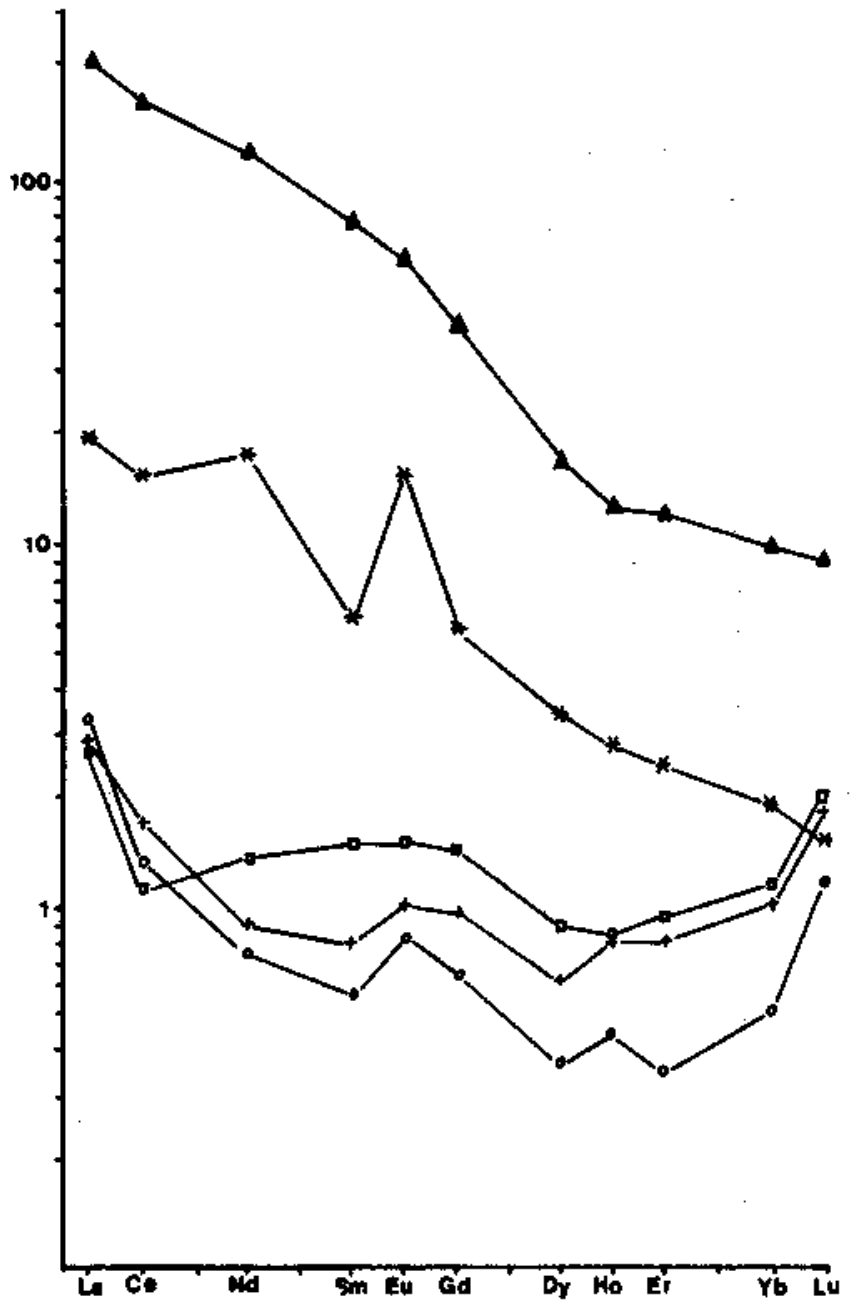

Figura 7 - Padrões ETR dos serpentinitos e das zonas metassomáticas de talco e de clorita xisto. A normalização foi realizada com valores de Masuda et al. (1973) divididos por 1,2 para aproximação com os valores dos condutos compostos. O valor de Ho é tomado de Evensen et al (1978) e multiplicado por 1,28 pela mesma razão. Clorita xisto ( $\Delta$ CS7.89g), Talco xisto (* CS $1.02 \mathrm{~m})$, Serpentinitos ( o CS1.02k, $\square$ CS2.05e, + CS4.72a)

Figure 7 - REE diagram of the serpentinites and some metasomatic zones. The normalization was preceded with Masuda's et al. (1973) values divided by 1,2 to approximate the compound condrites. Ho value is took from Evensen et al. (1978) and multiplied by 1,28 for the same reason. Chlorite schist $(\Delta$ CS7.89g), Talc schist (* CS1.02m), Serpentinites (O CS1.02k, $\square$ CS2.05e, + CS4.72a)

Protolito dos corpos de serpentinito A interpretação petrogenétíca através da utilização de dados geoquímicos de corpos ultramáficos, onde o processo de serpentinização está avançado ou completo, faz da serpentinização um processo dificil de ser trabalhado (Strieder 1992). Considerado separadamente, o estudo das possíveis mudanças químicas ocorridas durante a serpentinizacão sofre uma limitação importante na dificuldade de se fixar um "marcador inerte", através do qual estas mudanças químicas apareçam claramente, como foi verificado para o caso do processo metassomático debordo.

A utilização de elementos maiores como "marcadores inertes" deve considerar a variabilidade na proporção modal entre as fases minerais que compõem estas rochas e as possíveis variações de composição química destas mesmas fases minerais. Assim, à medida que se consiga homogeneidade modal e química da rocha ao longo de um único perfil de crescente serpentinização, é possível se obter uma boa resposta com o Diagrama Schteinberg (Fig. 8) e mostrar que a serpentinização pode ocorrer como um processo de simples adição de $\mathrm{OH}^{-}$ (Coleman \& Keith 1971). No entanto, a completa serpentinização dos corpos ultramáficos da região de Abadiânia não permite uma avaliação das condições químicas da serpentinização através dos elementos discutidos acima. Do mesmo modo, a utilização dos elementos menores como "marcadores inertes" da transferência de massa também deve requerer a análise de um perfil único de crescente serpentinização.

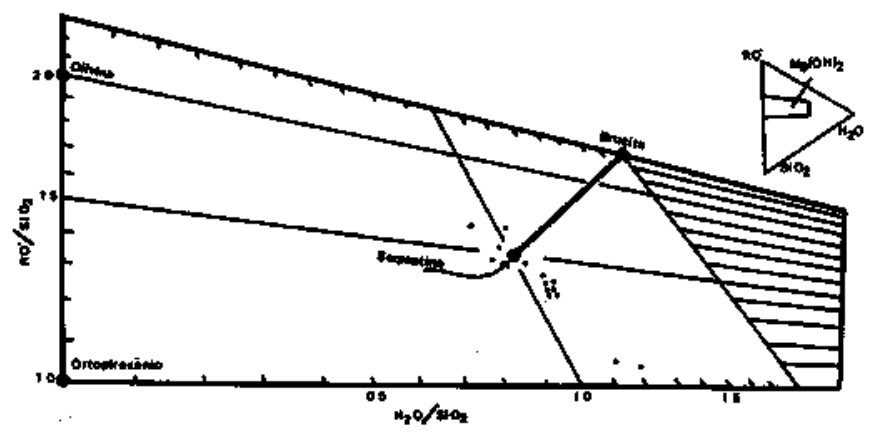

Figura 8- Diagrama molecular de Schteinberg para os serpentinitos

Figure 8 - Molecular Schteinberg diagram to serpentinites analysis

Deve-se, então, buscar outro "marcador inerte" através do qual se possa avaliar as condições químicas em que se processou a serpentinização. Para isso, será tentativamente utilizada uma correlação entre a composição química da cromita e das fases silicatadas em equilíbrio com a mesma (Irvine 1965, 1967); ou seja, a composição da cromita será utilizada para estimar a composição aproximada da olivina em equilíbrio e, pela comparação com os resultados obtidos da composição normativa dos serpentinitos, verificar as possíveis modificações químicas relacionadas ao processo de serpentinização. Assim, pretende-se utilizar a cromita como um "marcador inerte" indireto.

Inicialmente, é preciso observar que a correlação estabelecida por Irvine $(1965,1967)$ corresponde à olivina e à cromita acessória. A composição de cromitas da região de Abadiânia resulta de análises procedidas em cromititos maciços e disseminados e, portanto, é preciso discutir até que ponto esta composição pode ser usada com o objetivo aqui traçado.

A relação inversa na razão $\mathrm{Cr}^{3+} / \mathrm{Cr}^{3++} \mathrm{Al}^{3+}$ entre o crornitito e a cromita acessória (Leblanc et al. 1980, Cassard et al. 1981) não prejudica a análise neste aspecto, porque a evolução química das cromitas podiformes se faz aproximadamente ao longo das linhas equipotenciais de Irvine (1965). Ahmed (1984) desenvolve um detalhado estudo nos cromititos dó Complexo de Sakhakot-Qila e verifica não haver diferença na amplitude de variação da razão $\mathrm{Al}^{3+} / \mathrm{Al}^{3++} \mathrm{Cr}^{3+} \mathrm{Fe}^{3+}$, mas percebe haver um enriquecimento em $\mathrm{Mg}^{2+}$ nas segregações de cromita sem que fosse possível colocar um limite fixo entre ambas. Um limite superior de enriquecimento, como retirado dos dados de Ahmed (1984), situa-se em torno de 3-4\% peso de $\mathrm{MgO}$ e pode ocasionar diferenças médias de 0,1 na razão $\mathrm{Mg}^{2+} / \mathrm{Mg}^{2+} \mathrm{Fe}^{2+}$; contudo, conquanto isso possa significar uma superestimação dos teores de $\mathrm{MgO}$ da olivina, pode não ocasionar um erro maior do que aquele dado pela dispersão das análises.

A figura 9 fornece a composição química relativa das cromitas primárias na região de Abadiânia e mostra as linhas equipotenciais de correlação construídas a uma temperatura nominal de $1200^{\circ} \mathrm{C}$ por Dick \& Bullen (1984). Deste 
procedimento, resulta uma composição dispersa entre $\mathrm{Fo}_{88,0} \mathrm{e}$ $\mathrm{Fo}_{92,5}$ para as olivinas que comporiam a rocha hospedeira dos cromititos.

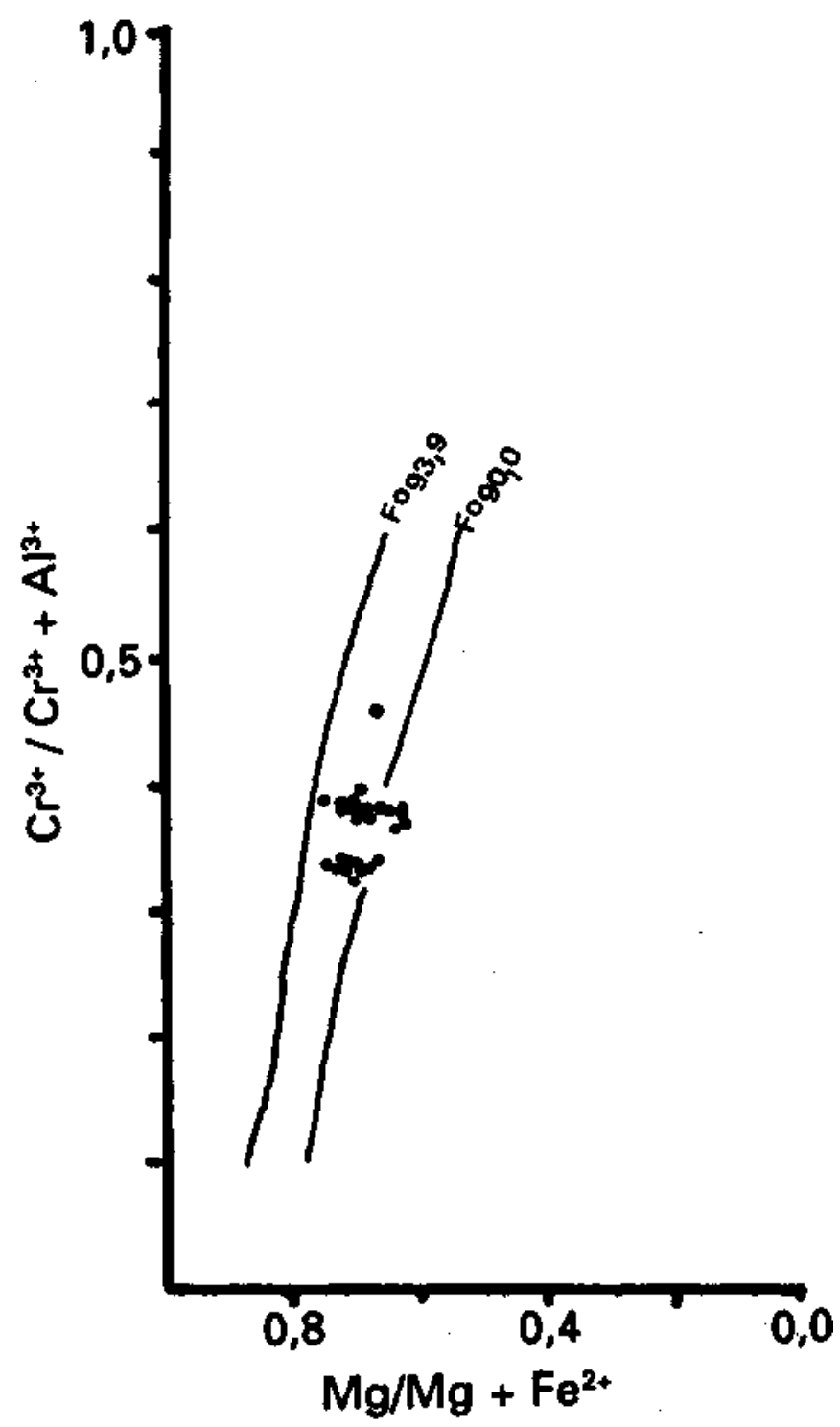

Figura 9 - Diagrama $\mathrm{Mg} \# x \mathrm{Cr}^{3+}$ \#para os núcleos de cromita. Linhas equipotenciais de Dick \& Bullen (1984)

Figure $9-\mathrm{Mg} \# \times \mathrm{Cr}^{3+} \#$ diagram for chromite centres. Equipotential lines from Dick \& Bullen (1984)

A tabela 3 apresenta as análises químicas dos serpentinitos da região de Abadiânia colocadas em forma de composição normativa segundo as condições especificadas no cabeçalho da figura. A composição das olivinas, obtidas por este procedimento, varia de $\mathrm{Fo}_{86.0}$ a Fo91,0.

A comparação dos resultados mostra um importante campo de superposição entre as composições F091.0 e Fo 8s,0. . Deve-se notar que a aparente discrepância nos resultados obtidos pelos dois procedimentos de estimativa pode ser a conseqüência do pequeno enriquecimento dos cromititos em $\mathrm{Mg}^{2+}$. Assim, a utilização da cromita como um "marcador inerte" indireto parece mostrar que não ocorreram mudanças significativas nos elementos químicos maiores durante a serpentinização, porque não houve, em termos gerais, mudança na razão $\mathrm{Mg}^{2+}$ $\mathrm{Mg} 2^{+} \mathrm{Fe}^{2+}$ da rocha envolvida. Além do mais, a composição normativa fornecida na tabela 3 representa uma rocha harz- burgítica, o que é coerente com a indicação da composição da rocha hospedeira fornecida pela composição altamente aluminosa dos cromititos.

A natureza dos serpentinitos da região de Abadiânia pode ser ainda indicada pela relação entre $\mathrm{NiO}$ e $\mathrm{Cr}_{2} \mathrm{O}_{3}$ apresentada na figura 10. Esta relação foi inicialmente apresentada por Malpas \& Stevens (1977) e, mais propriamente, distinguiu os peridotitos residuais "alpinos" e os peridotitos de complexos máfico-ultramáficos acamadados. Como o Ni tem um comportamento compatível em processos de fusão parcial (particionase preferencialmente para as fases sólidas), o alto conteúdo em $\mathrm{NiO}$ dos serpentinitos de Abadiânia também sugere uma natureza peridotitica residual para estas rochas.

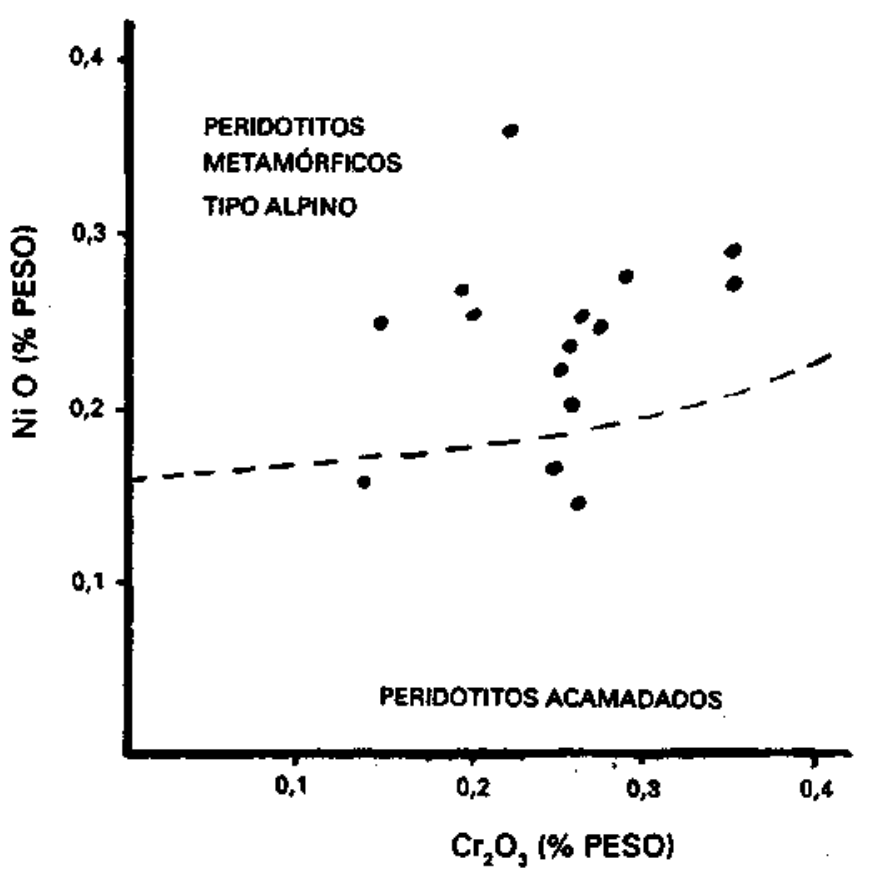

Figura 10 - Diagrama $\mathrm{NiO} \times \mathrm{Cr}_{2} \mathrm{O}_{3}$ que distingue peridotitos alpinos e peridotitos de intrusões acamadadas (Malpas \& Stevens 1977)

Figure $10-\mathrm{NiO} \times \mathrm{Cr}_{2} \mathrm{O}_{3}$ diagram to distinguish alpine from layered intrusion type peridotites (Malpas \& Stevens 1977)

Os resultados obtidos até aqui também são compatíveis com aqueles fornecidos pela figura 11. Nestes diagramas, os serpentinitos mostram uma composição química com pequena variação, que plota no restrito campo de peridotitos metamórficos (peridotito residual de manto). Se for considerado que a serpentinização e o metassomatismo de bordo fazem parte de um único processo de transformação metamórfica, deveria-se esperar que as amostras estivessem plotadas segundo uma direção de enriquecimento em $\mathrm{SiO}_{2}$ e empobrecimento em $\mathrm{MgÓ} \mathrm{no} \mathrm{campo} \mathrm{dos} \mathrm{cumulates} \mathrm{máficos} \mathrm{e} \mathrm{ultramáficos.}$

E necessário, ainda, discutir os padrões ETR medidos em algumas amostras, cujos resultados são fornecidos na figura 7. O resultado destas análises mostra um padrão ETR côncavo com conteúdo de Lu pouco variável e apresenta uma dispersão no conteúdo de ETRL, principalmente com relação ao La e ao Ce. Embora esse tipo de padrão seja consistente com aqueles fornecidos por harzburgitos de vários complexos ofiolíticos, as razões normalizadas $\mathrm{La} / \mathrm{Lu}$ dos serpentinitos de Abadiânia são maiores do que a razão condrítica. Assim, como os corpos ultramáficos de Abadiânia foram submetidos a serpentinização completa e metamorfismo de grau médio durante um longo período, faz-se necessário uma breve discussão acer- 
ca da influência da serpentinização sobre os padrões ETR apresentados.

Cinco amostras dos serpentinitos da região de Abadiânia, com crescente conteúdo de carbonato, foram submetidas a análise via ICR Duas destas amostras apresentaram teores em ETR abaixo do limite de detecção (Tab. 2). O padrão ETR das demais amostras (Fig. 7) apresenta um progressivo aumento no conteúdo de ETRL; a amplitude deste aumento causa uma modificação da característica côncava do padrão, principalmente na amostra CS2.05E. De um modo geral, não se verificou correlação entre o enriquecimento em ETRL e o conteúdo de carbonato, ou quaisquer dos elementos maiores. No entanto, ao se considerar a posição espacial das amostras dentro dos corpos de serpentinitos, evidenciou-se que o progressivo aumento no conteúdo de ETRL é dado pela proximidade dos bordos metassomáticos.

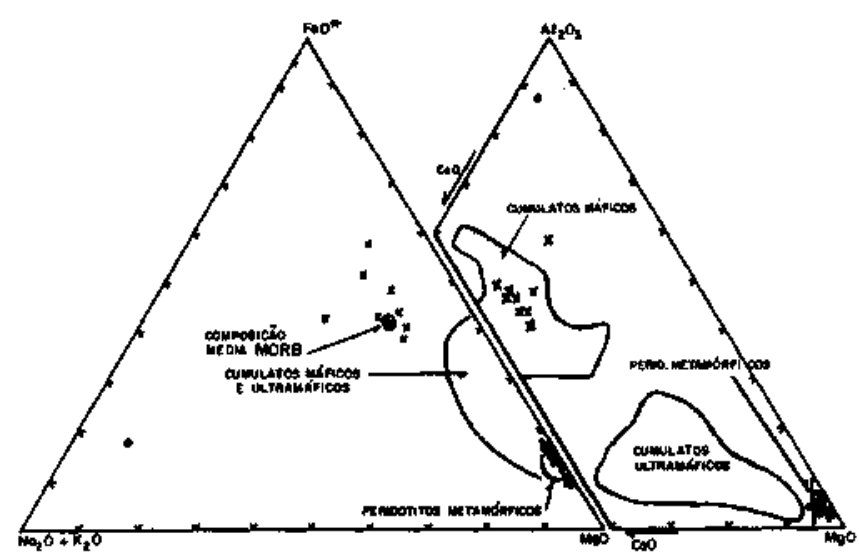

Figura 11 - Diagramas triangulares que distinguem os tipos de rochas máficas e ultramáficas de complexos ofiolíticos. (A) $\mathrm{MgO}-\mathrm{Al}_{2} \mathrm{O}_{3}-\left(\mathrm{Na}_{2} \mathrm{O}+\mathrm{K}_{2} \mathrm{O}\right)$ e (B) $\mathrm{MgO}-\mathrm{Al}_{2} \mathrm{O}_{3}-\mathrm{CaO}$. Omuscovita-plagioclásio-quartzo xisto, x epidoto-anfibólio xisto, -serpentinitos

Figure 11 - Triangular diagrams distinguishing types of mafic and ultramafic rocks from ophiolitic complexes. (A) $\mathrm{MgO}-\mathrm{Al}_{2} \mathrm{O}_{3}-\left(\mathrm{Na}_{2} \mathrm{O}+\mathrm{K}_{2} \mathrm{O}\right)$ e (B) $\mathrm{MgO}$ $\mathrm{Al}_{2} \mathrm{O}_{3}$-CaO. O muscovite-plagioclase-quartz schist, $\mathrm{x}$ epidote-amphibole schist, - serpentinite

O metamorfismo na região de Abadiânia, além da duração relativamente longa, desenvolveu-se sob condições oxidantes (Strieder 1989). Ottonello et al (1979), através do uso de diagramas Eh-pH, assinalam uma maior mobilidade química para os ETR sob estas condições. Assim, como a mobilidade dos ETR está ligada também à fase aquosa $(\mathrm{OH}-)$, pode-se admitir que a influência dos ETR da rocha encaixante avance adiante daquela dos elementos maiores no estabelecimento de equilíbrios parciais, porque estes últimos têm sua migração controlada preferencialmente por um processo de difusão intergranular (Brady 1977).

Entretanto, as modificações impressas no padrão ETR, principalmente das amostras CS1.02K e CS4.72A, não são expressivas a ponto de obliterarem completamente o padrão original. Os baixos teores normalizados de ETRP e ETRM parecem indicar que somente os ETR mais leves foram modificados e, portanto, sugerem uma afinidade harzburgítica residual, que é consistente com as várias linhas de evidência discutidas até aqui. Embora os dados disponíveis apontem sistematicamente para a interpretação dada acima, a completa caracterização do protolito dos corpos de serpentinito é uma tarefa difícil, porque a composição química é o único elemento disponível para se fazer esta caracterização. Os dados de composição minera- lógica, de petrotrama e de estruturas da rocha original foram completamente apagados devido serpentinização, ao metamorfísmo e à deformação.

A complexidade da estrutura e da composição da seqüência ultramáfica de diversos complexos ofiolíticos (Jacques \& Chappell 1980) pode resultar em alguma dispersão dos dados químicos e, caso a serpentinização esteja completa, causar dúvidas no tratamento petroquímico. Neste sentido, a identificação isolada de pseudomorfos grossos de piroxênio (enstatita alterada $<5 \mathrm{~mm}$ ) tem um significado difícil de avaliar, porque o tamanho grosso não é exclusividade de unidades cumuláticas, porque sua forma pode e deve estar modificada pelo desenvolvimento das texturas ribbon e lepidoblástica e porque a composição química global das rochas onde ocorrem não apresenta qualquer diferença no conjunto de análises. Desta mesma maneira, amostras que possuem um elevado conteúdo normativo de ortopiroxênio (CS1.02M e CS2.05F) pode-riam representar unidades piroxeníticas comuns na seqüência ultramáfica acamadada dos complexos ofiolíticos. Porém, esta caracterização é unicamente química, porque a intensidade do desenvolvimento da textura lepidoblástica $\mathrm{K}_{1}$ não permite o reconhecimento de qualquer pseudomorfo de piroxênio nestas amostras.

CONCLUSÕES Os nove corpos de serpentinito que ocorrem na região de Abadiânia (GO) registram todas as superfícies deformacionais também impressas nas rochas metassedimentares encaixantes; possuem, também, elementos texturais (textura ribbon) para sugerir o mecanismo de milonitização regional como o gerador da xistosidade $S_{1}$. As características petrográficas mostraram que a serpentinização e o metassomatismo estão temporalmente relacionados à fase de milonitização regional $\left(\mathrm{D}_{1}\right.$ e que a recristalização da antigorita é preferencialmente não-pseudomórfica (serpentinização do tipo 7 de Wicks \& Whittaker 1977).

A transferência bilateral de massa (metassomatismo) entre o serpentinito e a sua encaixante metassedimentar se deu sob as condições do fades epidoto-anfibolito (grau médio), o que resultou na formação de uma zona descontínua de tremolita+clinocloro; esta zona metassomática é o contato inicial entre a rocha ultramáfica e a sua encaixante. Por meio das razões atômicas, testou-se a mobilidade de elementos maiores e menores; por este procedimento, verificou-se que $\mathrm{Ni}^{2+}, \mathrm{Cr}^{3+}, \mathrm{Co}^{2+}$ e $\mathrm{Ti}^{4+}$ foram essencialmente imóveis durante a transferência de $\mathrm{Si}^{4+}, \mathrm{Al}^{3+}$ e ETRL em direção ao serpentinito e de $\mathrm{Mg}^{2+}$ em direção ao granada-mica-quartzo xisto encaixante.

A utilização da cromita como "marcador inerte" indireto parece indicar que não ocorreram mudanças apreciáveis na proporção relativa de $\mathrm{MgO}$ e de $\mathrm{FeO}^{*}$ dos serpentinitos durante o metamorfismo. Isto permitiu utilizar diagramas discriminantes que indicam uma afinidade geoquímica com os peridotitos residuais de manto para os serpentinitos. A composição normativa dos serpentinitos indica uma rocha harzburgítica e isto está de acordo com a composição altamente aluminosa dos cromititos. O padrão de ETR, embora com um pequeno enriquecimento em ETRL, ainda permite identificar a forma côncava muito empobrecida presente neste tipo de rocha.

Agradecimentos Os autores gostariam de agradecer à Metais de Goiás S.A. pelo suporte financeiro aos trabalhos de campo em Abadiânia durante o período 1987-1988 e ao CNPq (Processo 408044/86.1), que viabilizou as análises químicas contidas neste trabalho. Gostariam, também, de agradecer ao Prof. Raul Minas Khuyunjian (I.G. - UnB) pela leitura e pelas sugestões para o aprimoramento do texto. 


\section{REFERÊNCIAS BIBLIOGRÁFICAS}

AHMED, Z 1984. Stratigraphic and textural variations in the chromite composition of the ophiolitic Sakhakot-Qila Complex, Pakistan. Econ. Geol, 79(6): 1334-1359.

BATISTA, M.B. 1969. Projeto Goiania - Folha Morrinhos. Rio de Janeiro, PROSPEC/DNPM-MME. 31 p. (Relatório Preliminar).

HERBERT C.0.1970. Geologia dos complexos básicos-ultrabásicos de Goiás. In: CONOR. BRAS. GEOL., 24. Brasília, 1970. Atas... Brasília SBG/CO.p.41-50.

BERBERT, CO.; CORRÊA, J.A.; MELO, J.C.R. 1970. Geologia da Área de Interlândia-Abadiânia, Goiás. Rio de Janeiro, DNPM-MME. 59 p. (Boletim 135).

BOAVENTURA, G.R. \& HIRSON, J.R. 1987. Amostras de referência geoquímica para controle de análises de rochas. In: CONGR. BRAS. GEOQ., 1. Porto Alegre, 1987. Anais... Porto Alegre, SBGq. v. 2, p. 321-326.

BRADY, J.B. 1977. Metasomatic zones in metamorphic rocks. Geochim. Cosmochim. Acta, 41(1): 113-125.

BRAUN, O.P.G. 1969. Projeto Goiânia - Folha Ipameri. Rio de Janeiro, PROSPEC/DNPM-MME. 42 p. (Relatório Preliminar).

CASSARD, D.; NICOLAS, A.; RABINOVITCH, M.; MOUTTE, J.; LEBLANC, M.; PRINZHOFFER, A. 1981. Structural classification of chromite pods in Southern New Caledonia. Econ, Geol., 76(5):805-831.

COLEM AN, R.G. \& KEITH, T.E. 1971. A chemical study of serpentinization Burro Mountain, California. J. Petrol., 12(2):311-328.

CORRÊA, J. \& BITTENCOURT, CM. 1968. Mapeamento Geológico da Área Goiânia-Bonfinópolis, Goiás. Rio de Janeiro, DNPM-MME. 71 p. (Boletim 134)

DANNI, J.C.H. \& TEIXEIRA, N.A. 1981. Características e sistematização das associações de rochas máficas e ultramáficas Pré-Cambrianas do Estado de Goiás. In: SIMP. GEOL. CENTRO-OESTE, 1. Goiânia, 1981. Atas.. Goiânia, SBG. p. 376-401.

DICK, H.J.B. \& BULLEN, T. 1984. Chrornian spinel as a petrogenetic indicator in abyssal and alpine-type peridotites and spatially associated lavas. Contr. Mineral. Petrol, 86(1):54-76.

DRAKE, A.A.Jr. 1980. The Serra de Caldas Window, Goiás. Washington, U.S. Geol. Survey, p. M1. (Prof. Paper 1119/A-B).

EVANS, B.W. 1977. Metamorphism of alpine peridotite and serpentinite. Ann Rev. Earth. Planet. Sci., 5:397-447.

EVENSEN, N.M.; HAMILTON, P.J.; O'NIONS, R.K. 1978. Rare-earth abundances in chondritic meteorites. Geochim. Cosmochim. Acta, 42:1199-1212.

FOWLER, M.B.; WILLIAMS, C.T.; HENDERSON, P. 1983. Rare earth element distribution in a metasomatic zoned ultramaphic pod from Fiskenaesset, West Greenland. Mineral. Mag., 47(3):547-553.

GANGULY, J. 1968. Analysis of the stabilities of chloritoid and staurolite and some equilibria in the system $\mathrm{FeQ}-\mathrm{Al}_{2} \mathrm{O}_{3}-\mathrm{SiO}_{2}-\mathrm{H}_{2} \mathrm{O}-\mathrm{O}_{2}$. Am. J. Sci., 266(2):277-298.

GANGULY, J. 1969. Chloritoid stability and related parageneses: theory, experiments and applications. Am. J. Sci., 267:910-944.

GANGULY, J. 1972. Staurolite stability and related parageneses theory, experiments and application. J. Petrol., 13(3):335-365.

HUMPHRIS, S.E. 1984. The mobility of the rare earth elements in the crust. In: HENDERSON, P. ed. Rare Earth Element Geochemistry. Amsterdan, Elsevier.p.317-342.

IRVINE, T.N. 1965. Chromian spinel as a petrogenetic indicator. Part 1: theory. Can. J. Earth Sciences, 2(4):648-672.

IRVINE, T.N. 1967. Chromian spinel as a petrogenetic indicator. Part 2 petrology application. Can. J. Earth Sciences, 4(1):71-103.

JAQUES, A.L. \& CHAPPELL, B.W. 1980. Petrology and trace elements geochemistry of the Papuan Ultramaphic Belt. Contr. Mineral. Petrol., 75(1):55-70.
LEBLANC, M.; DUPUY, C.; CASSARD, D.; MOUTTE, J.; NICOLAS, A.; PRINZ HOFFER, A.; RABINOVITCH, M.; ROUTHIER, P. 1980. Essai sur la gen'ese des corps podiformes de chromitite dans les p'eridotites ophiolitiques: etude des chromites de Nouvelle-Calédonie et comparaison avec celles de Mèditerrane Orientale. In: PANAYIOTON, A. ed. Proceeding of the Intermational Ophiolite Symposium. Cyprus, 1979. p. 691-701.

LIOU, J.G. 1973. Synthesis and stability relations of epidote, $\mathrm{Ca}_{2} \mathrm{Al}_{2} \mathrm{FeSi}_{3} \mathrm{O}_{12}(\mathrm{OH})$. J. Petrol, 14(3):291-412.

LIOU, J.G.; KUNIYOSHI, S.; ITO, K. 1974. Experimental studies of the phase relations between greenschist and amphibolite in a basaltic system. Am. J. Sci., 274(5):613-632.

MALPAS, J. \& STEVENS, R.K. 1977. The origin and emplacement of the ophiolite suite with examples from Western Newfoundland. Geotectonics, 11(6):453-466.

MALTMAN, A.J. 1978. Serpentine textures in Anglesey, North Wales, United Kingdom. Geol. Soc. Am. Bull, 89(7):972-980.

MASUDA, A.; NAKAMURA, N. \& TANAKA, T. 1973. Fine structures of mutually normalized rare-earth patterns of chondrites. Geochim. Cosmochim. Acta, 37(1):238-248.

NILSON, A.A. 1981. The nature of the Americano do Brasil MaficUltramafic Complex and Associated Sulfide Mineralization, Goiás, Brazil Ontario-Canada. 460 p. (PhD Thesis, University Western Ontario).

NILSON, A. A. 1984.0 atual estágio de conhecimento dos complexos máficoultramáficos Pré-Cambrianos do Brasil - uma avaliação preliminar. In: CONGR. BRÁS. GEOL., 33. Rio de Janeiro, 1984. Anais... Rio de Janeiro, SBG. v. 4, p. 4166-4203.

NILSON, A.A. \& MOTTA, J. 1969. Geologia da Área de Goianira-Trindade Goiás. Rio de Janeiro, DNPM-MME. 108 p. (Boletim 133).

OTTONELLO, G. PICCARDO, G.B. ERNST, W.G. 1979. Petrogenesis of some Ligurian peridotites, II: rare earth element chemistry. Geochim. Cosmochim. Acta, 43(5): 1273-1284

SANFORD, R.F. 1982. Growth of ultramafic reaction zones in greenschist to amphibolite facies metamorphism. Am. J. Sci., 282(3):543-616.

STRIEDER, A.J. 1989. Geologia, Petrologia e Tectônica dos Corpos de Serpentinito e Rochas Encaixanies, Abadiânia (GO). Brasília. 208 p. (Dissertação Mestrado, IG/UnB).

STRIEDER, A.J. 1990. Análise estrutural da região de Abadiânia (GO). Rev. Bras. Geoc., 20(1-4):239-257.

STRIEDER, A.J. 1992 Serpentinização e metassomatismo em rochas ultramáficas discussão das características e recomendações para o tratamento geoquímico. Rev. Bras. Geoc. 22(3):329-337.

STRIEDER, A.J. \& NILSON, A.A. 1991. Melange ofiolítica nos metassedimentos Araxá de Abadiânia (GO) e implicações tectônicas regionais. Rev. Bras. Geoc., 22(2): 204-215.

TROMMSDORFF, V. \& EVANS, B.W. 1974. Alpine metamorphism of the peridotitic rocks. Schweiz. Mineral. Petrol. Mitt., 54(2/3):333-352.

WICKS, F.J. \& WHITTAKER, E.J.W. 1977. Serpentinite textures and serpentinization. Can. Mineral., 15(3):459-488.

WINKLER, H.G.F. 1978. Petrogéneses de Rocas Metamórficas. Madrid, H. Blume ed. 346 p. (Trad. C. Casquet \& M. Peinado).
MANUSCRITO A725

Recebido em 19 de marco de 1992 Revisão do autor em 2 de julho de 1992 Revisão aceita em 14 de julho de 1992 